\title{
Adolescent substance use in relation to school-based extracurricular activities according to individual and school-level characteristics
}

\author{
Kari L. Maxwell \\ West Virginia University
}

Follow this and additional works at: https://researchrepository.wvu.edu/etd

\author{
Recommended Citation \\ Maxwell, Kari L., "Adolescent substance use in relation to school-based extracurricular activities \\ according to individual and school-level characteristics" (2009). Graduate Theses, Dissertations, and \\ Problem Reports. 757. \\ https://researchrepository.wvu.edu/etd/757
}

This Thesis is protected by copyright and/or related rights. It has been brought to you by the The Research Repository @ WVU with permission from the rights-holder(s). You are free to use this Thesis in any way that is permitted by the copyright and related rights legislation that applies to your use. For other uses you must obtain permission from the rights-holder(s) directly, unless additional rights are indicated by a Creative Commons license in the record and/ or on the work itself. This Thesis has been accepted for inclusion in WVU Graduate Theses, Dissertations, and Problem Reports collection by an authorized administrator of The Research Repository @ WVU. For more information, please contact researchrepository@mail.wvu.edu. 


\title{
Adolescent Substance Use in Relation to School-Based Extracurricular Activities According to Individual and School-Level Characteristics
}

\author{
Kari L. Maxwell \\ Thesis submitted to the \\ College of Human Resources and Education \\ at West Virginia University \\ in partial fulfillment of the requirements for the degree of \\ Master of Arts \\ In \\ Educational Psychology
}

\begin{abstract}
Dr. Carol Markstrom, Ph.D., Chair
Dr. Kristin Moilanen, Ph.D., Committee member

Dr. Jennifer Adams, Ph.D., Committee member

Department of Technology, Learning, and Culture
\end{abstract}

Morgantown, West Virginia

2009

Keywords: Adolescence; Substance use; Extracurricular Activities; Socioeconomic status 


\begin{abstract}
Adolescent Substance Use in Relation to School-Based Extracurricular Activities According to Individual and School-Level Characteristics
\end{abstract}

\author{
Kari L. Maxwell
}

The purpose of this study was to fill gaps in previous literature on adolescent involvement in activities that are school-based in relation adolescent alcohol, tobacco, marijuana, and illicit substance use, while taking into account important individual and sociodemographic variables. Research was conducted with 49 12th grade students in two public high school in North Central West Virginia. Data were collected using an internet questionnaire accessible to students on Survey Monkey. The questionnaire consisted of tobacco, alcohol, marijuana, and illicit drug use questions that were derived directly from the Youth Risk Behavior Survey (YRBS) questions pertaining to students involvement in school-based activities during the past school year. The present study tested three separate hypotheses. The first hypothesis was that higher rates of involvement in extracurricular activities would be associated with lower levels of substance use. The present study found statistically significant negative relationships between involvement in school-based activities and tobacco and alcohol use. The second hypothesis was that males would report higher levels of substance use than females, especially males involved in sports activities. A hierarchical regression analyses showed that the addition of gender and sports involvement into the model did not explain a significant portion of the variance in tobacco, alcohol, or illicit drug use. Finally, the third hypothesis was that adolescents from the lower SES school would have higher rates of substance use than those adolescents from the higher SES school. Three separate meanlevel comparisons by school found that students from the lower SES school were not significantly more likely to use cigarettes, alcohol, or illicit drugs than students from the lower SES school. Result findings are discussed in relation to implications of the study, study limitations, and recommendations for future research. 


\section{ACKNOWLEDGEMENTS}

What should be the easiest part of this paper to complete has become my biggest struggle to even begin. The process of earning this degree and finishing this thesis has been supported by many people beginning several years ago. From my professors to friends and family- I can not put into words how thankful and grateful I am for your support throughout this entire process.

I am thankful to my thesis committee for their motivation, hard work, encouragement, and guidance while completing this thesis. To Dr. Carol Markstrom for providing me with hours and hours of guidance in turning this paper into something meaningful. To Dr. Kristin Moilanen for being my statistician and for her expertise in research and all the knowledge and skill that she has brought to this department and program the past year. And to Dr. Jennifer Adams for her expertise in writing and her knowledge of working with high school students. Additionally, I am grateful to the other faculty members of the program, especially Dr. Amy Root for the never ending encouragement and emotional support of getting through a very strenuous process.

I don't feel like this acknowledgement would be complete without thanking Dr. Richard Calef and the rest of the Psychology department faculty members at WV Wesleyan College for teaching me the theses process. During those four undergraduate years, I never understand why Dr. Calef was so critical of my writing style, but because of him I had the confidence, experience and knowledge to complete this thesis.

To my family- most of all, my husband, for being my rock. Without his encouragement and emotional and mental support, I would have never made it to this point in my education. I can not count the number of nights he'd tell me, "you can do it" and offer his assistance in any 
way possible. To my son, while he's been too young through the process to be supportive-- he is the reasoning of all my hard work. Watching him grow from a newborn to a toddler in the past 15 months has given me the strength and motivation to stay focused on my studies. I know that one day when he's old enough and understands, he will be proud of his mommy and I can't wait to see him graduate from college. Finally, this thesis would have never been completed without the help of the rest of my family, especially my mom, Cheryl Bramble, and mother-in-law, Dianna Maxwell, for taking my son for several hours weekly to allow me to attend class and have time to write and study throughout the past two years. There is no way I would be done without their love, encouragement, and babysitting deeds. No amount of words or space would allow me to explain what my family means to me and what they have done for me to help me get to this point. I owe a portion of this degree to every single one of them. 
Table of Contents

Page

Title Page

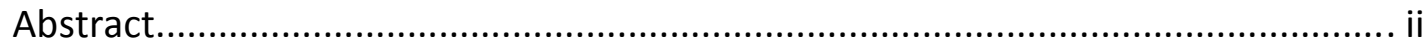

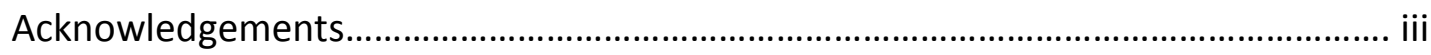

Table of Contents...........................................................................................

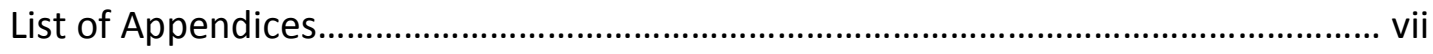

List of Tables and Figures......................................................................................... viii

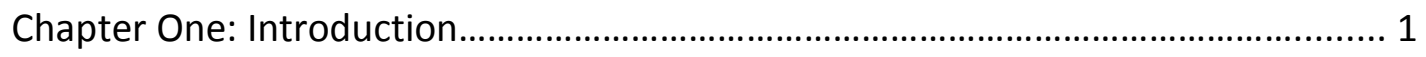

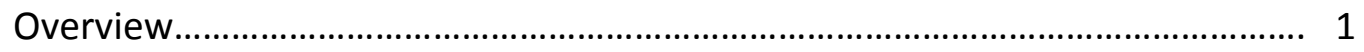

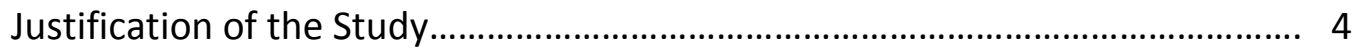

Statement of the Problem and Purpose ......................................................... 5

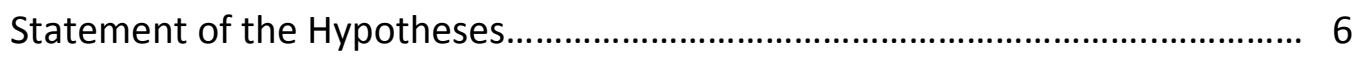

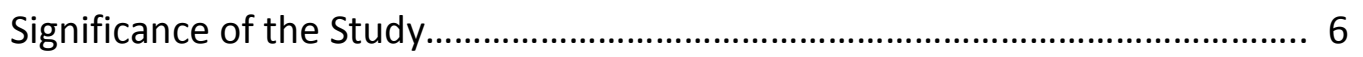

Chapter Two: Review of Literature ................................................................. 7

Trends in Adolescent Alcohol, Tobacco, and Drug Use and Abuse................... 7

Theoretical Framework......................................................................... 9

Hirschi's Social Control Theory......................................................... 9

Bronfenbrenner's Ecological Systems Theory.................................... 12

Participation in Structured Activities and Substance Use and Abuse.............. 19

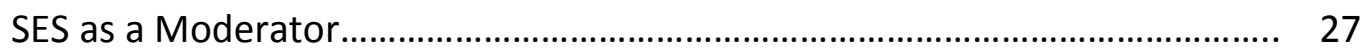

Chapter Three: Methodology......................................................................... 33

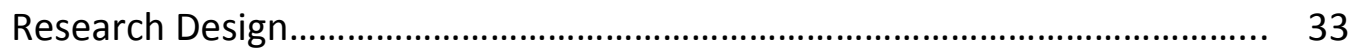

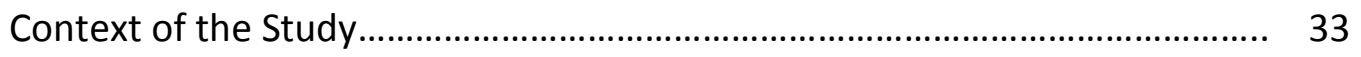




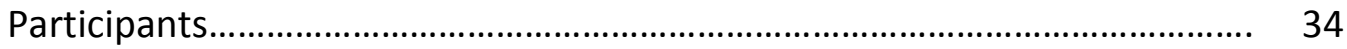

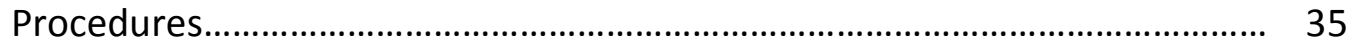

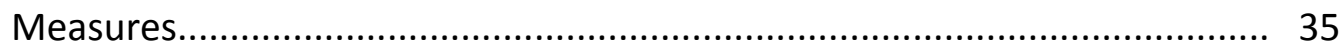

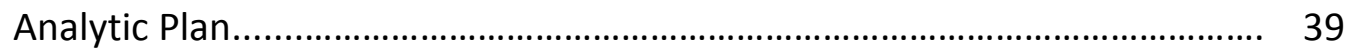

Chapter Four: Results........................................................................... 41

Preliminary Analyses............................................................................. 41

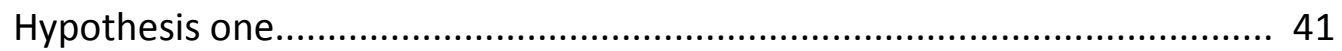

Hypothesis two............................................................................. 41

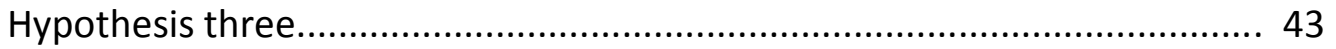

Chapter Five: Discussion....................................................................... 45

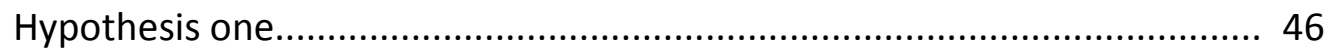

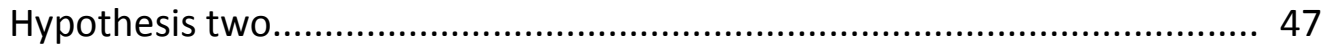

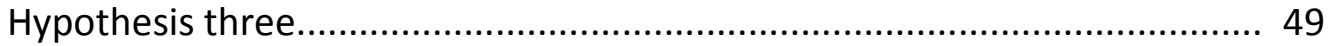

Implications of Research Findings...................................................... 53

Limitations and Conclusions....................................................... 55

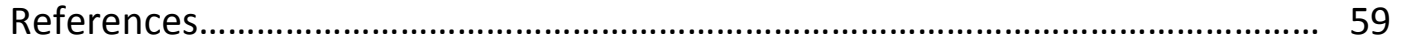




\section{Appendices}

Appendix A: Permission from county Superintendent............................. 74

Appendix B: Permission from WVU (IRB) ............................................ 76

Appendix C: Recruitment invitation....................................................... 78

Appendix D: Adolescent Questionnaire Measure....................................... 80 
List of Tables and Figures

Table $\quad$ Page

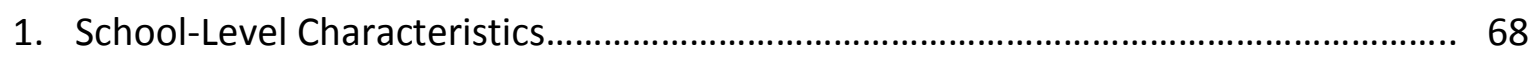

2. Study Variable Descriptive Statistics by School and Full Sample............................ 68

3. Bivariate Correlations for School-Based Involvement with Cigarette, Alcohol, and Illicit Drug Use........................................................................................... 69

4. Summary of Hierarchical Regression Analyses for Variables Predicting Cigarette, Alcohol, and Illicit Drug Use............................................................................... 70

5. Cigarette, Alcohol, and Illicit Drug Use Means for School A (Low SES)

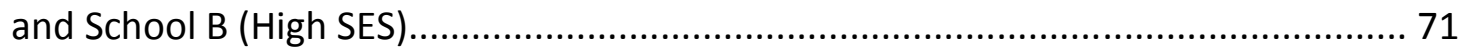

Figure

1. Ecological Systems Theory Based off of Bronfenbrenner's Theory (1986)................ 72

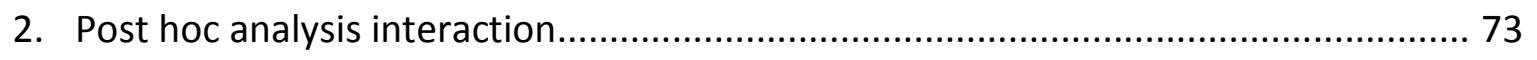


Chapter One

Introduction

\section{Overview}

Adolescence is characterized as the period in one's life between childhood and adulthood. One developmental milestone and purpose of adolescence is preparation for adulthood. With this transition, numerous cognitive, socioemotional, and biology changes occur. During this period, adolescents are faced with many challenging decisions that will essentially affect their future as adults. However, numerous factors can either positively or negatively influence these decisions. Adolescents are faced with new experiences, one of which is the use and abuse of tobacco, alcohol, and other drugs. Knowledge of how adolescents become involved in substance use and abuse, why they decide to use and abuse drugs, and ways to protect adolescents from these harmful influences is essential to adolescent research.

Adolescence is the peak period for initiation to alcohol use, resulting in alcohol being the most widely used drug in the United States by adolescents (D'Amico \& McCarthy, 2006). Alcohol is described as a gateway drug that sometimes leads to experimentation with marijuana and other illegal substances (Wagner \& Anthony, 2002). Therefore, research on adolescent alcohol use is essential to preventing initiation into other types of drugs. In addition to the introduction of alcohol, tobacco use is also a common trend seen in adolescence. According to Santrock (2007), smoking is likely to begin in grades seven through nine and tobacco has been cited as the most frequently used substance by high school seniors on a daily basis. Alcohol, tobacco, and illicit drug use are seen across all contexts and demographics of adolescents. 
Adolescents use and abuse drugs for many reasons; for instance, because drugs help them to adapt to the multiple changes occurring during this period. Smoking, drinking, and using drugs also relieve tension and stress, and such substances are often used to escape the harshness of life, especially for those who have an unstable family lifestyle (Santrock, 2007). However, another reason many adolescents engage in substance abuse is to reduce boredom. This reasoning has led to numerous research studies on the ways in which adolescent spend and occupy their free time. Extracurricular activities, doing homework, and other activities that are socially acceptable are viewed as a constructive use of time and protective factors for engagement in substance use and abuse (Barnes, Hoffman, Welte, Farrell, \& Dintcheff, 2007). Regardless of the type of substance being used and the reasons for their use, experimentation and initiation into the involvement of these substances should not be taken lightly. Most drugs have a strong influence on behavior and brain activity including impaired perception and thought processes, and even damaging and killing brain cells (Santrock, 2007). A distinction should be made between the use of substances and the abuse of substances. Out of curiosity and/or peer pressure, the majority of adolescent may use a substance on occasion or at least try it. The majority of these adolescents are psychologically healthy, sociable, curious young people (Berk, 2007) who are not headed towards a lifestyle of drugs, sex, and rock $\mathrm{n}^{\prime}$ roll, per se. Unfortunately, a number of adolescents do eventually become substance abusers. Substance abuse can be described as taking drugs on a regular basis, becoming dependent on the substance to function, creating family, life, school, and work problems, requiring increasing amounts of the substance to achieve the same effect, and greater risk for using harder substances (Berk, 2007). According to the Diagnostic and Statistical Manual of 
Mental Disorders IV (American Psychiatric Association, 1994, Diagnostic and statistical manual of mental disorders) substance abuse is defined as; the (a) recurrent use resulting in failure to fulfill major role obligations at work, home or school; (b) recurrent use in physically hazardous situations; (c) recurrent substance related legal problems, or continued use despite persistent; or (d) recurrent social oar interpersonal problems caused or exacerbated by substance in a 12month period. It is these at-risk adolescents that demonstrate the necessity to conduct research and discover methods that will prevent problem substance behaviors.

Studies regularly indicate that adolescents who participate in school-based extracurricular activities obtain many benefits from involvement in these activities including less involvement in risk behaviors and less substance use and abuse (Crosnoe, 2002; Eccles et al., 2003; Hoffman \& Xu, 2002; Mahoney, 2000; Mahoney and Cairns, 1997; Mahoney, Cairns, and Farmer, 2003). Accordingly, most schools offer a variety of activities in which students can become involved. According to Darling (2005, p. 493),

School-based extracurricular activities provide adolescents with a high structured leisure environment, in which adolescents an exert control and express their identity through choice of activity and actions within the setting, but which do not normally facilitate experimentation with roles and activities that are not sanctioned by adults.

Interestingly, about 70 percent of mainstream United States students are involved in some type of school-based extracurricular activity such as athletics, clubs, drama, and student government (Hoffman, 2006). Accordingly, Eccles and Barber (1999) reported that more than 50 percent of students participate in school-sponsored athletics. As will be discussed in the following chapter, rates of substance use continue to be higher in the United States than most other 
countries, even though there has been a decline of tobacco, alcohol, and drug use and abuse over the past few decades. If the majority of students are currently involved in school-based extracurricular activities and the literature reports that involvement in these activities reduces the likelihood of substance use and abuse, then why are the rates of adolescent substance use and abuse still high? This question addresses the importance of looking to possible moderators and mediators of substance use and abuse. The present study will attempt to address both individual (e.g. age, gender, and SES) and school-level (e.g. school SES, ethnic composition, and graduation rate) and community (median income) characteristics. These variables will be discussed further in the following chapter. Justification of the Study

Research on substance use is an important theme in adolescent literature. While most research has found that involvement in school-based extracurricular activities is a protective factor for adolescent substance use, rates of adolescent substance use and abuse continue to be high. The literature cited in the following chapter will reveal several discrepancies according to the type of drug being used (alcohol, tobacco, marijuana, and illicit substances), the type of activities in which the adolescent is involved (athletics, clubs, etc), and sociodemographic factors such as gender, age, and socioeconomic status in relation to substance use and abuse. For example, Darling (2005) found that adolescents participating in extracurricular activities reported lower levels of smoking and marijuana use, but not alcohol use. In a few cases, extracurricular participation has been linked to negative adolescent outcomes and higher involvement in risk behaviors. Numerous researchers have found that males have higher rates of alcohol and drug use (Harnett, Thom, Herrin \& Kelly, 2000; Lorente, Peretti-Watel, Griffet \& 
Frelot, 2003). These discrepancies in past literature lead to a need for further examination of the role of school-based extracurricular activities in adolescent substance use and abuse in addition to the family, school, and community contexts in which they occur.

\section{Statement of the Problem and Purpose}

There is an ever increasing demand to understand factors that influence adolescents' decisions to engage in substance use and to research alternatives to substance use that protect adolescents. According to the results from the 2007 Youth Risk Behavior Survey (YRBS, 2007), West Virginia students are at high risk for involvement in substance use and abuse and this problem needs to be addressed. The present study will investigate the association between adolescent substance use and abuse and involvement in school-based extracurricular activities. Four types of adult-sponsored structured activities will be considered in relation to substance use and abuse in adolescence: namely, community-based activities, sport activities, performing arts, and academic clubs. These organized activities were selected because of the devotion and commitment required of the adolescent for involvement and because they allow adolescents to express their passions and identities (Eccles \& Barber, 1999).

The purpose of this study was to fill gaps in previous literature on adolescent involvement in school-based extracurricular activities in relation adolescent alcohol, tobacco, marijuana, and illicit substance use, while taking into account important individual and sociodemographic variables. In this paper, the characteristics of the schools, such as socioeconomic status, ethnic composition, graduation rate, and location will also be addressed. An examination of the specific type of activity involvement and its correlation to the type of drug being used will also be observed. 
Statement of the Hypotheses

It was hypothesized that: (1) higher rates of involvement in school-based extracurricular activities would be associated with lower levels of substance use and abuse; (2) based on research on the influence of gender (Crosnoe, 2002), males involved in sports activities would report a greater likelihood of substance use and abuse; and (3) fbased on research by Hoffman and Xu (2002), Hoffman (2006), and Wilson, Syme, Boyce, Battistich, and Selvin (2005), adolescents from the lower SES school and neighborhood would have greater rates of substance use and abuse than those adolescents from the higher SES school and community. Significance of the Study

This study is significant because: (1) it has increased the general knowledge base in the research of adolescent substance use, at least, narrowing the gap in the previous literature on the relationship of involvement in school-based extracurricular activities with substance use; (2) it has narrowed the gap in previous literature on the possible moderators and mediators of adolescent substance use; (3) it has offered evidence to schools, parents, students, and communities about the nature of these relationships and differences; and (4) it has offered a reference for future research that might investigate the same variables. 


\section{Chapter Two}

\section{Review of Related Literature}

The objective of this chapter is to review literature that is relevant to the present study. This prospectus reviews and cites literature that formed the basis of the investigation. First, the chapter begins with a description of the current trends in adolescent alcohol, tobacco, and drug use and then is followed by the theories being utilized to explain the positive effects of adolescent involvement in school-based extracurricular activities and substance use. In this prospectus, Hirschi's (1969/2002) social control theory, Bronfenbrenner's (1986) ecological systems theory, and current literature in the human development field are reviewed to provide a theoretical and empirical basis for the present research. Finally, a review of related research and their findings is examined for further support of the key aims of the present study including research on the participation in school-based extracurricular activities and substance use. The chapter concludes with a discussion of relevant literature on SES as a moderator of involvement in school based extracurricular activities on substance use.

Trends in adolescent alcohol, tobacco, and drug use and abuse

According to a recent survey of U.S. high school students, 40 percents of adolescents have smoked cigarettes, 63 percent have drunk alcohol, and 38 percent have used at least one illegal drug by the time they reach the tenth grade. By the end of high school, 14 percent of students smoke on a regular basis, 28 percent have engaged in binge drinking, and over 50 percent have experimented with illegal drugs (Berk, 2007). While there continues to be a decline over the past several years, rates of substance use and abuse still presents worrisome numbers on the amount of adolescents using substances. As Santrock (2007) points out, "The 
United States still has one of the highest rates of adolescent drug use of any industrialized nation" (p. 475). Communities and schools have spent millions of dollars to produce programs to teach adolescents and their families parenting styles, ways to resist peer pressure, reducing the social acceptability of drug use by placing emphasis on the health risks, and getting adolescents to commit to not using drugs. However, these prevention strategies are not $100 \%$ effective; therefore more successful and cost-effective strategies must be developed. While the incidence of adolescent substance use and abuse may not be evenly distributed across states, cities, ethnicities, gender, SES, etc., according to the 2007 Youth Risk Behavior Survey, the rural state of West Virginia reports high risk rates among its high school students.

Trends in adolescent substance abuse in the United States and by individual states are examined with the Youth Risk Behavior Survey (Centers for Disease Control and Prevention, 2007). The Youth Risk Behavior Survey (YRBS) is given every two years to students in grades 9 through 12 in public schools. This national survey monitors health risk behaviors that contribute to the leading causes of death, disability, and social problems among adolescents and adults in the United States. Two sections of the survey are specifically designed to monitor tobacco, alcohol, and other drug use.

When comparing West Virginia students and U.S. students, the 2007 YRBS revealed that West Virginia students were at greater risk for lifetime cigarette use, current cigarette use, current smokeless tobacco use, episodic heavy drinking, lifetime cocaine use, lifetime methamphetamine use, lifetime inhalant use, and being offered, sold, or given an illegal drug by someone on school property. West Virginia students were at an equal risk for lifetime alcohol use, current alcohol use, and lifetime marijuana use compared to other students in the 
U.S. These results demonstrate the need for parents, teachers, schools, and communities of West Virginia youth to find ways to decrease substance use.

\section{Theoretical Framework}

The two central concepts -involvement in school-based extracurricular activities and school and community-level demographics_-being addressed in relation to adolescent substance use can be examined through the theoretical frameworks of Hirschi's (1969/2002) social control theory of delinquency and Bronfrenbrenner's (1986) ecological systems theory. Hirschi's social control theory should support the idea that involvement in school-based extracurricular activities decreases the likelihood that adolescents will use and abuse alcohol, tobacco, and other drugs. The hypothesis that students in the lower socio-economic (SES) school and community along with related demographic issues will have a greater probability of substance use and abuse, can be theoretically supported by examining Bronfrenbrenner's ecological systems theory.

Hirschi's social control theory. Hirschi's (1969/2002) social control theory revolves around the idea that deviant behavior occurs when the adolescent has a weak or negative bond to society. There are four key elements that help an individual achieve a healthy bond to society: attachment, commitment, belief, and involvement. Each of these is defined in the following paragraphs.

Attachment refers to the positive bonds that an adolescent forms with his/her parents, school, and peers. For example, many past researches have shown that parental attachment is inversely related to the use of alcohol and drugs in adolescence (Kostelecky, 2005; Parker \& Benson, 2004; Van der Vorst, Engels, Meeus, \& Dekovic, 2006; Walsh, 1995). The stronger the 
adolescent's attachment to others, including the school, parents, peers, and community, the less likely the adolescent will deviate from the norms of what is expected of their behavior. Participating in extracurricular activities enhances the adolescent's ability to get to know other peers and adults through personal bonding and mutual trust and commitment. Getting involved in extracurricular activities is a way for students "to develop mentoring or coaching relationships, develop personal relationships with peers who share similar interests, and possibly interact with other adults from the school or community who provide support for the activity" (Feldman \& Matjasko, 2005, p. 162).

The element of commitment refers to a commitment to individuals or institutions that maintain the normative order. According to Hirschi (1969/2002), a person who is committed to being a positive model to society by becoming educated, starting a family, and maintaining a career, will abstain from behaviors that could result in a negative societal status. This element is represented in the literature by findings that suggest academic achievement and academic expectation is correlated to less substance use and abuse (Jeynes, 2002; Rao, 2001). It would also be of importance to those with high levels of commitment to be involved in activities that will strengthen the adolescent's chances of obtaining his/her goal career.

Belief describes the degree of trust that the individual has in the society and the amount of acceptance in the rules created by those in the society (Hirschi, 1969/2002). People are more likely to not deviate from the rules and laws if they agree with the rules and the people who enforce them. Rules exist in all institutions: the family, school, community, state, government, etc. While these three elements contain components that relate to the 
adolescent's involvement in activities and the way they are affected by their environment, Hirschi specifically identifies the fourth element as involvement.

Involvement will be the main element which the present study will address.

Involvement refers to the time adolescents spend on activities that society finds socially acceptable. These activities include sports, school clubs, church involvement, family activities, and other societal activities. According to Hirschi (2002), "a person may be simply too busy doing conventional things to find time to engage in deviant behavior" (p. 22). According to this theory, the use of alcohol and other drugs is related to the amount of involvement in these conventional activities. Adolescents who frequently participate in organized activities have less free time to abuse drugs and alcohol. The reverse is that adolescents not involved in organized activities have less structured time with peers and adults and, therefore, have plenty of time to consume alcohol and drugs. Involvement in these activities also supports the other three elements - attachment, commitment, and belief. Conventional activities are not only a way for adolescents to make positive use of their time, but also involve a commitment to the team, club, etc. and a belief in the rules and regulations that are attached to the activity.

Extracurricular activities offer a means for adolescents to increase social and human capital, leading to positive attachment with his/her family, school, and peers. Activities that are schoolbased extracurricular activities give adolescents more positive role models and adults to confide in when faced with decisions about substance abuse.

Hirschi's (1969/2002) social control theory supports the idea that an adolescent's involvement in activities and the way the adolescent interacts and believes in his/her community will affect decisions that adolescents face concerning drugs and alcohol. To take a 
more complete perspective on the school and community demographics and the roles of the school, family, and community affecting these adolescents' substance use and abuse decisions, this article will use Bronfenbrenner's (1986) ecological systems theory for support. Widely studied and accepted risk and protective factors will be described while examining the ecological systems theory.

Bronfenbrenner's ecological systems theory. According to Bronfenbrenner and Morris (1998), development is optimized when individuals engage in activities that can grow with the developing individual; however, the individual must have a supportive community in which to grow. Bronfenbrenner's theory suggests that the adolescent's surroundings including his/her home, school, work, peers, community, church, etc. will all have an influence on the way an adolescent develops. It is suggested that if the adolescent grows up in a high risk environment that his/her development will be influenced in a negative manner, leading to lower self-esteem (Kohr, Colderon, Skiffington, Masters, \& Blust, 1988; Richman, Clark, \& Brown, 1985), health problems such as depression, high blood pressure, and obesity (Goodman, 1999; Treiber, 1999), and increased stress (Adler, 1999; Bradley \& Whiteside-Mansell, 1997; Shonkoff \& Phillips, 2000). Components of a high risk environment include low socio-economic status (SES), high crime rate, little opportunity to engage in structured activities, and a lack of support from others. According to the theory, these environmental characteristics can lead to an adolescent's proclivity to engage in unhealthy life choices, especially substance abuse. According to Wills (1995), higher rates of substance abuse have been reported for low-SES teens. Bronfenbrenner's theory and its application to the present study are examined in the following paragraphs. 
Bronfenbrenner's theory consists of four individual but reciprocal systems that make up a person's surroundings, environment, and values. These four systems are the microsystemthe settings with which the developing adolescent interacts; the mesosystem - the relations between microsystems or connections between contexts; the exosystem - settings with which the individual does not interact but nevertheless affect the adolescent; and the macrosystemcultural values and larger societal factors that influence the adolescent (See Figure 1). Each system directly or indirectly influences the adolescent and, therefore, can influence his/her decision to abuse alcohol and drugs. The ways in which each system affects adolescents' risk behaviors are discussed.

Before examining the four social contexts of the ecological systems theory, it is also important to examine the individual factors related to the adolescent him/herself. Several individual risk factors have been identified in past literature on adolescent substance abuse. Some of these variables that apply to the adolescent self are age, gender, and family income. Callen (1985) reports that adolescents between the ages of 16 and 18 are at the highest risk for initiation into substance use. Callen (1985) also reports that the risk of trying other illicit drugs is highest at age 18. Gender predicts the probability of substance abuse. Most studies have found that a greater number of males abused alcohol and other drugs than females (LeaverDunn, Turner, \& Newman, 2007; O’Malley, Johnston, \& Bachman, 1998). Family income has been shown to play a significant role in the extent to which adolescents use substances (Bradley \& Corwyn, 2002; Hanson \& Chen, 2007; Wilson, Syme, Boyce, Battistich, \& Selvin, 2005). Research has found that declining economic opportunities and low family income could damage family structure and processes that often serve as protective factors for adolescent 
substance abuse. Adolescents from low SES backgrounds may experience barriers such as lack of transportation, financial requirements, and more personal home responsibilities that prevent involvement in extracurricular activities (Markstrom, Li, Blackshire, \& Wilfong, 2005). There have been numerous variables that researchers have identified as risk factors for substance abuse, although some discrepancies amongst sociodemographic factors exist in the literature. In this study, age, gender, and community SES will be examined.

The system primarily addressed in this study will be the microsystem. Paquette and Ryan (2001) describe the microsystem as the layer closest to the adolescent containing entities such as the family, school, and community, with which the adolescent has direct contact. Research suggests that the role of the parents and family is critical in keeping adolescents safe and away from drugs. Lohman and Billings (2008) identified numerous protective factors in the microsystem: academic expectations, academic achievement, school recognition, parental monitoring, family routines, and parent-child relationship. Structures of the microsystem have the most extensive research in the substance use research field. The family has a strong influence on whether the adolescent will become involved with substance abuse. Direct family influences can also be explained by the social control theory. Social ties to the family and other institutions of the microsystem that promote conventional norms and values deter youths from risky behaviors. Connections to parents can also restrain adolescents even in the midst of negative peer pressure (Hirschi, 2002).

Schools and communities are other sources of socialization and support for adolescents. Often, when the family is dysfunctional, the school becomes an important socializing agent and can help protect those adolescents who are high-risk. Adolescents who believe they are 
receiving high levels of support in school and feel that they are connected to teachers are less likely to engage in risk behaviors (Resnick \& Bearman, 1997). The community could also act as a risk factor or a protective factor for adolescents. Within the schools and community are the adolescent's closest friends. Peers have a strong influence on the choices adolescents make concerning substance use. Research shows that if adolescents observe their friends acting on risk behaviors, then they will adopt the same type of behaviors (Crosby et al., 2000; Voisin, 2003.) However, while the institutions in the microsystem are often protective factors, there are several risk factors that can be involved, as well. Poor neighborhood quality has been linked to substance abuse (Brewster et al, 1993; Roche et al, 2005). In addition, numerous schools do not have the funding to offer opportunities and involvement in school-based extracurricular activities. The current study will attempt to address demographics of the schools and communities within which adolescents live. A current analysis and comparison of the schools and communities' statistics will be discussed later in this thesis.

The next level, the mesosystem, describes how the different parts of the adolescent's microsystem work together for the sake of the adolescent. For example, the parent's involvement or lack of involvement in the teenager's school is part of the mesosystem which could affect the adolescent's healthy decisions. If parents are not involved in the other parts of the adolescent's life, then parental monitoring is lacking, leaving the adolescent at risk for early substance abuse (Santrock, 2007). Parental monitoring is an important protective factor. Evidence shows that when parents are involved in the adolescent's life by knowing where they are, who their friends are, and what they are doing, the parents are decreasing the likelihood of their adolescent becoming involved in alcohol and drugs (Cottrell et al, 2007; DiClemente et al, 
2001). The family can also play an important role in encouraging the adolescent to get involved in extracurricular activities in the school and community. If the family does not support the adolescent then the adolescent will likely not be an active participant in activities. The school, community, and family must work together to promote a healthy environment for the teenager.

The exosystem is described as the level that may or may not involve the developing person as an active participant but in which events occur that affect, or are affected by, what happens in that setting. These are the environments in which adolescents do not actually spend their time, but are affected by what occurs in the environment. There are three exosystems that have been identified to likely affect the development of the adolescent: namely, the parents' workplace, the parents' social networks, and community influences on family functioning (Bronfenbrenner, 1986). This system is also known as the socioeconomic context of a child (Boyd \& Bee, 2006). An example, suggested by Boyd and Bee (2006), would be the funding for education existing in the socioeconomic context. SES, school, and community play roles in the success of adolescents and therefore can either be protective or risk factors affecting the likelihood of substance abuse. Relative to Hirschi's social control theory, if the family, school, and community do not have the funding, availability, and accessibility to support adolescents' involvement in these extracurricular activities (i.e. due to low family and school SES), then those adolescents are already at a disadvantage. Subsequently, adolescents then have more free time to engage in these risk behaviors due to a lack of other recreational and culturally acceptable activities. 
Other ways in which the exosystem influences adolescent substance abuse is through government laws on the legal drinking age and illegal drugs. Government laws are clear about the minimum age for alcohol consumption and the illegality of all illicit drugs. However, mixed messages about alcohol and drugs are being sent to adolescents because the media (Santrock, 2007) shows professional athletes, actors, musicians, and celebrities partaking in alcohol and drugs. These people serve as role models for adolescents and when the media glorifies alcohol and drug use and shows these models having a good time while consuming these substances, then it is contributing to the adolescent substance abuse problem. While this system will not be examined directly in this study, it should be noted that the exosystem can indirectly affect the other systems, thereby, influencing the adolescent's development.

The final system, the macrosystem, is the outermost layer in the adolescent's environment. This layer is comprised of cultural values, customs, and attitudes of the norm of society. The government laws are reflective of the norm of the culture that adolescents should not be participating in the consumption of these substances. Deviations from these cultural norms are viewed as unsafe and unhealthy for the positive development of the adolescent. This layer affects the family structure and provides the cultural norms that the family is expected to live by. The culture expects the family to take responsibility for raising their children; therefore, parents are responsible for protecting their adolescent from substance abuse. Along with the exosystem, the macrosystem will not be directly examined in the present study. However, it is important to remember that all of systems in the bioecological systems theory work together, thereby, affecting each other. 


\section{Summary}

Through the examination of both the social control theory and ecological systems theory and review of relevant research studies, it is evident that a multitude of individual behaviors as well as school and family microsystem factors have been related to adolescent substance use and abuse. Bronfenbrenner's ecological systems theory (1986) supports the aim of the present study by pointing to the importance of the systems on the positive development of the adolescent. The systems theory emphasizes the influence of the schools and communitys when comparing rates of adolescent substance use. The systems that the adolescent is part of can act as important protective factors relative to substance use.

The social control theory, specifically, points to the involvement of adolescents in school-based extracurricular activities as a protective factor for substance abuse. Involvement in school-based extracurricular activities exposes students to conventional peers and positive adult role models who can motivate and encourage the adolescent to engage in healthy behaviors rather than substance use (Eccles et al., 2003). Social control theory argues that a lack of involvement in socially-acceptable organizations such as schools explains the proclivity for risk behaviors in adolescence to emerge. Students involved in extracurricular activities develop conventional bonds with positive adult role models and peers, therefore reaping the social benefits of involvement and leading to less risk behaviors such as substance use. Accordingly, involvement in activities is also related to the time adolescents spend engaging in conventional activities. Adolescents who spend less time in these school-based extracurricular activities have more opportunities to take part in unhealthy behaviors such as substance use (Hirschi, 1969). 
In summary, bioecological systems theory is relevant in the present study because it gives indication on specific systems that influence adolescent substance use. The system primarily addressed in this study will be the microsystem; specifically, the influence of the school and community contexts. The school and community are important sources of socialization and support in adolescence, therefore, having a strong influence on the adolescent development. While the bioecological systems is the framework for why the current study will be addressing individual, school, and community variables, social control theory explains why involvement in school-based extracurricular activities can protect against adolescent substance use. In general, the social control theory is used as a basis to explain why involvement in school-based extracurricular activities may act as a buffer to adolescence risk behaviors. Participation in School-Based Extracurricular Activities and Substance Use

Adolescence is a susceptible period of time when experimentation with alcohol, tobacco, and other illicit drugs occurs. Research documents the relations between adolescent participation in school-based extracurricular activities and substance use (Crosnoe, 2002; Eccles et al., 2003; Hoffman and Xu, 2002; Mahoney, 2000; Mahoney and Cairns, 1997; Mahoney, Cairns, and Farmer, 2003). Studies indicate that students who participate in extracurricular activities derive a host of benefits including higher rate of college attendance rate, higher grade point average, lower dropout rate, higher self esteem, and less involvement in substance use and abuse and delinquent behaviors (Crosnoe, 2002; Eccles et al., 2003; Hoffman and Xu, 2002; Mahoney, 2000; Mahoney and Cairns, 1997; Mahoney, Cairns, and Farmer, 2003). Research also suggests that participation in school extracurricular activities may be more advantageous for students from lower-socioeconomic status (SES) families and schools compared to those 
from higher SES backgrounds (Guest and Schneider, 2003; Hoffman, 2006; Marsh and Kleitman, 2002). Many exceptions and discrepancies exist in the literature; namely (a) sociodemographic factors such as gender and age, (b) the effect of involvement according to the particular substance being used and/or abused, and (c) the type of involvement (sports involvement compared to nonsports involvement).

Most of the literature reviewed in this chapter utilizes data from longitudinal and correlational research. In addition, the literature demonstrates the many moderators and mediators (e.g., gender, age, type of involvement, type of substance) that must be examined when studying adolescent substance use and abuse. The previously mentioned theories are also well-supported by past literature.

Mahoney (2000) conducted a longitudinal study examining the associations between child and adolescent participation in school-based extracurricular activities and patterns of antisocial behavior from childhood to young adulthood was conducted among 695 males and females. The participants were interviewed annually from childhood to the end of high school and again at ages 20 and 24. During each interview and assessment of the participant, numerous measures were taken. Mahoney (2000) found that participation in one or more school extracurricular activity before the $11^{\text {th }}$ grade was associated with reduced rates of both criminal activity and early school dropout rates. However, when looking at antisocial patterns of participants, a decrease in these patterns was only shown in those participants whose social network also participated in school extracurricular activities. A participant's social network was defined as being involved in school activities if at least half of all the students that the 
participant identified as a person who they "hang out with" participated in extracurricular activities for one or more years.

In a similar longitudinal study, Darling (2005) addressed the issue of participation in school-based extracurricular activities and the associations with lower levels of substance use. Extracurricular activity participation was measured by student reports of participation during the current school year. Using a 4-point scale, adolescents were asked to report how often they used alcohol, used tobacco, smoked marijuana, or used a drug other than marijuana since the beginning of the current school year. Adolescents who participated in extracurricular activities reported lower levels of smoking, marijuana use, and use of other drugs when compared to students who did not participate in extracurricular activities during the present school year. There were no differences in alcohol use among students who participated in extracurricular activities and those who did not.

Leaver-Dunn, Turner, and Newman (2007) studied the protective effects of involvement in recreational activities on alcohol abuse and intention of use. Differences in alcohol use and intentions to abuse alcohol was investigated through a sample of 1,690 adolescent males who participated in school-based sports, community-based sports, and/or school-or-communitybased clubs and organizations compared to those adolescents who did not participate in any recreational activities. The study found that club members were significantly less likely to drink alcohol or binge drink than non club members. Club members also reported a significantly lower intention to drink alcohol than non-club member. Participants involved in extracurricular activities were less likely to use or intend to use alcohol. The study found no differences in 
alcohol use in adolescents who participated in sports activities and those who did not participants in sports.

While Leaver-Dunn et al. (2007) examined the specific types of activities, Harrison and Narayan (2003) categorized adolescents into four types of involvement: namely, only sports involvement, only extracurricular activities, both sports and other extracurricular activities, or no participation. Researchers examined the type of involvement in relation to higher levels of psychosocial functioning and healthy behavior. The Minnesota Student Survey, comprised of questions to examine school climate and perceptions, use of free time, family and relationships, physical and mental health, physical and sexual abuse, substance use, and sexual activity, was administered to 50,168 ninth grade students throughout Minnesota's public schools. Level of participation in school sports or other extracurricular activities was developed from a set of questions where students were to answer how many hours a week they spent doing certain activities; namely, sports, band, choir, orchestra, music lesions, practicing voice or an instrument, clubs or organizations outside of school or volunteer work or community service. Substance use was based on the Monitoring the Future format (MTF). The MTF has been used to measure drug, alcohol, and cigarette use and attitudes about substance use among students nationwide. The survey asks participants to report their drug use behaviors across three time periods: lifetime, past year, and past month. Consistent with past research, participation in sports only or in conjunction with other activities was related to plenty of exercise, consumption of milk, a healthy self-image, and a lower probability of emotional distress, suicidal behavior, familial substance abuse, and a history of physical and sexual abuse. The study found that students involved in activities, sports and other extracurricular activities, were 
less likely to skip school, get into fights, vandalize property, smoke cigarettes or marijuana, binge drink, or have sexual intercourse.

While most studies on adolescent substance abuse have examined high school students, Shilts (1991) administered the Alcohol and Drug Use Index and the Student Attitude and Behavior Questionnaire, to 237 middle school students in Virginia. The purpose of the study was to observe relationships between early adolescents' involvement in extracurricular activities, peer influence, and attitudes toward their drug and alcohol use. The Alcohol and Drug Use Index found that 107 of the students were nonusers, 80 were users, and 50 were abusers. Results revealed that the nonusers group reported significantly higher involvement in extracurricular activities when compared to the other two groups. In summary, the author found that those adolescents who did not use alcohol and drugs were highly involved in extracurricular activities and spent more time with their family and less time with friends.

Research studies generally support the idea that adolescent involvement in extracurricular activities sponsored by school are considered safeguards against risk-taking behavior and the kind of peer influence that leads to substance abuse (Crosnoe, 2002; Eccles et al., 2003; Hoffman and Xu, 2002; Mahoney, 2000; Mahoney and Cairns, 1997; Mahoney, Cairns, and Farmer, 2003). However, it is necessary to examine the literature that does not support this idea. In a statewide study of $3,18911^{\text {th }}$ grade public high school students in a large Midwestern state conducted by Borden, Dennermeyer, and Scheer (2001), the effect of extracurricular activities was less important than the influence of peers for explaining variance in substance use. In addition, several other studies have also shown that sports participation is 
related to higher levels of alcohol use (Crosnoe, 2002; Eccles \& Barber, 1999; Zill, Nord, \& Loomis, 1995).

Using data from the Michigan Study of Adolescent Life Transitions, Eccles and Barber (1999) examined the potential benefits and risks associated with participation in five types of involvement; specifically, prosocial, team sports, school involvement, performing arts, and academic clubs. The study found that males involved in the performing arts reported a lower probability of drinking alcohol. In contrast, participation in sports was associated with an increase use of alcohol. Participation in out-of-school activities such as church, communityservice, and volunteering, were found to not be associated with the likelihood of alcohol, marijuana, and illicit drug use. Participation in school-related clubs and nonathletic activities was not related, positively or negatively, to engagement in alcohol, tobacco, marijuana, or illicit drug use.

Cooley, Nelson, and Thompson (1995) explored the relationships between extracurricular activities and adolescent drug and alcohol use using a 52 item questionnaire. The sample was comprised of 5,639 students in grades 5 through 12 who participated in sports, clubs, and music/drama. Cooley et al. (1995) examined the relationship between substance abuse with the type of specific involvement. Results showed that experimentation with tobacco was greater among those involved in sports than participation in clubs, music/drama, or multiple activities. While experimentation and use of alcohol were common among all extracurricular activities, alcohol use was highest for athletes. When comparing the type of activity, marijuana use was highest for seniors who participated in music/drama. However, it was found that marijuana use was greatest for students who did not participate in any 
extracurricular activities. In general, students not participating in extracurricular activities were more likely to experience and use illicit drugs, including inhalants, depressants, hallucinogens, over-the-counter drugs, and cocaine) than those students participating in extracurricular activities.

Research studies have sampled adolescent males to look at the correlation between involvement in athletics and substance use, however, Perry-Burney and Takyi (2002) sampled female high school students. All females reported playing in team school sports throughout their high school career. Rather than using a survey or questionnaire to address substance abuse, the females were asked to tell the interviewers about their use of drugs and alcohol. Findings show that sports participation was associated with less drug or alcohol use.

As can be seen, mixed support for the idea that sports involvement decreases the likelihood of substance use and abuse exists. While the majority of the cited literature shows an association between sports involvement and less illicit drug use, less smoking, and less marijuana use (Hoffman \& Xu, 2002; Mahoney, 2000; Mahoney, Cairns, \& Farmer, 2003), some literature has found that the use of alcohol is higher among students who participate in team sports when compared to other adolescents (Crosnoe, 2002; Eccles \& Barber, 1999; Eccles et al., 2003). Crosnoe (2002) postulated the reasoning behind the association of higher alcohol use among students participating in school team sports stating: "Athletes are usually the most popular students, and since alcohol use is generally a high-status social activity during this stage, athletes' drinking may reflect their social centrality. Alcohol may impair academic and athletic performance, but these risks may be downplayed by considerations of social standing" (p. 332). This high social standing and popularity amongst athletes is accompanied by a greater 
tendency to attend parties where alcohol is served. Another possible explanation for this discrepancy is the availability of alcohol. Many athletic events become atmospheres where alcohol is supported and the norm for that event, leading to an easier availability of alcohol (Hoffman, 2006). While parents are trying to tell adolescents to stay away from drugs and alcohol, alcohol is served at weddings, graduation parties, athletic events, and other rites of passages leading to easier availability of alcohol, especially among those in the high social standing class of their school and communities.

In an attempt to address gender discrepancies in the influence of sports involvement on substance abuse, Crosnoe (2002) examined differences among males and females using data from a longitudinal study of adolescent functioning. Crosnoe found that gender did not moderate tobacco use; however, alcohol use differed according to gender, specifically higher for males. Crosnoe found that participation was associated with a lower probability of early illicit drug use among males and to a lower likelihood of illegal drug use over time among females. The study supported the social bond theory by demonstrating that "athletic participation promotes academic achievement by integrating students into school" (pp. 331).

In summary, evidence of an association between participation in school-based extracurricular activities and adolescent substance use has been demonstrated in many of the previous cited studies. However, inconsistency exists in the literature on the effects of participation in athletics when compared to other extracurricular involvement, as well as the effect of participation on the type of substance being used or abused. An aim of the present study will be to address these discrepancies while examining whether certain 
sociodemographic variables such as gender, age, and socioeconomic status influence the degree of adolescent substance use and abuse.

\section{SES as a moderator}

Researchers have found that, among adults, lower SES is associated with higher substance use (Adler, Boyce, Chesney, Cohen, Folkman, Kahn, 1994; Lantz, Lynch, House, Lepkowski, Mero, Musick, 2001). However, limited research exists on the association of both individual/family SES and school and community SES on the prevalence of substance abuse among adolescents.

Hanson and Chen (2007) tested the association between family SES and substance use in adolescents. One hundred and thirteen public high school students were asked to report their tobacco, alcohol, and drug use behaviors using the Health Behaviors Questionnaire. Parents were asked to provide information on four factors: parent education, occupation, family income, and savings. These four factors were then computed using the Hollingshead Four Factor Index of Social Status to develop the family social status. The results found that higher SES adolescents reported more tobacco, alcohol, and drug use when compared to the lower SES students. These results do not support the literature on adult substance as discussed in the previous paragraph. The authors speculated that a possible reason for this discrepancy is that adolescents from higher SES families may feel safer experimenting with substances or may suffer from achievement pressures and isolation from adults (Luthar \& Becker, 2002; Luthar \& Latendresse, 2005). Adolescents in higher SES families have privileges that low SES families cannot afford such as having a vehicle, allowing for easier accessibility to substances and more freedom. 
While the previous study measured and looked for associations among family SES and substance use and abuse, a key aspect of this thesis was to explore associations among substance use and school and community characteristics such as school SES, ethnic composition, graduation rate, and community median household income. It is important to consider these school and community SES levels because there is evidence that these contexts are associated with health, achievement, and behavioral outcomes even when family SES are controlled for (Bradley \& Corwyn, 2002; Leventhal \& Brooks-Gun, 2000). The relationship between substance use and the social context in which substance use occurs are important to consider in adolescent substance use research. These social contexts influence the manner in which parents raise their children, the expectations of the adolescent in the school and community, the resources of the school and community, and the level of danger (Wilson, Syme, Boyce, Battistich, \& Selvin, 2005). Attitudes about school differ between adolescents which can influence their decisions to be involved in school extracurricular activities. For some, schools provide a place of belonging, a place where they are respected and accepted; however, others find school wearisome and display a strong dislike for school (Hoffman, 2006). Low family SES has been associated with less family satisfaction and turmoil and stress amongst the family (Stamm, 2003). It would be believed that these adolescent's, from families where turmoil and stress are prevalent, would be those who find school as a place of belonging - a place to escape from the stresses of their home life. These attitudes could affect the adolescent's involvement in activities and the likelihood of substance use.

Wilson et al. (2005) investigated the relationship between adolescent substance use and their perception of community disorder and sense of hope. According to the authors, 
“...people with fewer resources have a reduced capacity to overcome the more difficult and serious hardships in their lives, which is exacerbated by fewer opportunities for quality education and adequate employment. These resources, as well as levels of community poverty, are directly related to levels of health, sense of well-being, and sense of control over one's life" (Wilson et al., 2005, p. 12).

In this study, participants were asked to respond to a seven-point scale on the frequency of alcohol, tobacco, and marijuana use. Students also were asked to indicate how often they witnessed people in their neighborhood drinking alcohol, getting robbed, using drugs, being arrested, stealing, fighting, and helping each other which created the community disorder variable. Results demonstrate that as the level of reported community disorder increased, the greater the proportion of adolescent substance use was reported. A strong relationship between alcohol, tobacco, and drug use and community disorder was found. Community disorder was highest amongst those communities with lower overall SES.

Therefore, those adolescents from lower SES communitys who reported increased community disorder reported a greater likelihood of substance use.

In an exploratory study by Person, Sweeting, West, Young, Gordon, and Turner (2006), adolescent substance use was investigated in relation to different social and peer contexts. Using the "Teenage Health in School" data, the adolescents were administered a questionnaire asking questions involving family, life at school, lifestyles, self-esteem, substance use, and friendships. School SES was based on the proportion of students who receive clothing grants. Students in higher SES schools were more likely to have a large peer group and to report high popularity. Of importance to the study was the finding that among students from the lower SES 
schools, rates of tobacco use were lower among those students with higher popularity. Males from higher SES schools illustrated a higher rate of tobacco use. Similarly, popular males in the higher SES schools had higher levels of drug use, although this finding was opposite among females who had the lowest level of drug use. The most at-risk category for drug use was found among girls from low SES schools who reported low popularity and few friendships.

In an extensive review of literature, Hanson and Chen (2007) wanted to determine the direction of associations between SES and health behavior, including cigarette smoking, alcohol consumption, and marijuana use, during the period of adolescence. When reviewing studies focusing on the association between SES and cigarette smoking during adolescence, $71 \%$ of the studies found a negative association between SES and cigarette smoking; more specifically, that low SES adolescents are more likely to smoke than high SES adolescents. Amongst the studies looking at the association of SES and alcohol consumption, $69 \%$ of the studies found no significant association between SES and alcohol use. This finding suggests that alcohol consumption is not significantly associated with SES during adolescence. Similarly, $58 \%$ of the studies reported no significant association between SES and marijuana use. According to these past studies, it appears that no significant association exists between SES and marijuana use during adolescence. Hanson and Chen (2007) speculate that the reason for finding no significant association between SES and alcohol and marijuana use is that during adolescence, the influence of peers and the social standing of the adolescent amongst his/her school and peers are more influential as opposed to family SES.

Of most importance and relevance to the present study, Hoffman (2006) examined the relationship of adolescent alcohol use and involvement in extracurricular activities within 
school-contextual characteristics. Utilizing longitudinal data from the 1990-1992 National Educational Longitudinal Study, 5,398 female and 4,495 male high school students were analyzed on reported measures of alcohol use and participation in athletic activities and nonathletic activities. School variables that were assessed were school SES (determined by the percent of students who received free or reduced price lunch), school minority status, student/teacher ratio, type of school (public, private, or Catholic), school size, and school location. Findings indicate that involvement in nonathletic activities among males was associated with lower rates of alcohol usage. However, for both males and females, athletic involvement was associated with increased alcohol use. In relation to school SES, female sports involvement was associated with increased alcohol use to a greater extent in low-SES schools than in high- SES schools. Among males, involvement in sports was associated with a greater likelihood of alcohol use in high-SES schools than in low-SES schools.

\section{Summary}

In summary, this chapter provided the reader with a review of literature as related to the current study. Both the theoretical models and the review of previous literature will be utilized to explain the relationship of involvement in school-based extracurricular activities on adolescent substance use behaviors. Generally, the previous reviewed studies support the theoretical models of both the bioecological systems theory and the social control theory and are accepted in the literature to identify the variables that influence a positive adolescent development. While adolescence has been reported as a time of proclivity and initiation into substance use, many protective factors have been identified to guard adolescents from becoming involved in such behaviors. Involvement in school-based extracurricular activities is 
one key protective factor and has been found to be associated with less substance use and abuse amongst adolescence. However, several risk factors including age, gender, and family SES are present in the literature. The literature reports discrepancies amid these risk factors which need to be addressed. This chapter also served the purpose of allowing the researcher to draw on past literature to develop the methodological design for the present study. Accordingly, the researcher collected survey data from students from two North Central West Virginia High Schools. 


\section{Chapter Three}

\section{Methodology}

\section{Research Design}

This study utilized aspects of both non-experimental correlational and causalcomparative research designs. Self-reported cross-sectional data from adolescents from two high schools was used to investigate the association of adolescent substance use and involvement in school-based extracurricular activities. School characteristics were obtained from the county board of education website, and community characteristics were obtained from www.city-data.com, an online website that collects and analyzes data from numerous sources to create profiles for United States cities.

\section{Context of the Study}

Research was conducted with 12th grade students in two high schools in north central West Virginia. The high schools were chosen as a convenience sample for the researcher. They were also chosen because the schools are in very close proximity to one another, they have very similar curricula, and offer the same opportunities for school activity involvement. Of significance, the two schools differ on important sociodemographic characteristics, most particularly number of students receiving free or reduced price lunch, past graduation rates, and test scores. In addition, the median household income for School A community was $\$ 34,377$, while the median household income for School B community was $\$ 61,148$. This household income distinction accounted for almost $\$ 27,000$ difference between the two communities. Overall, the distinct differences in the characteristics of the schools were expected to support the idea that contexts such as school and community have an influence on 
adolescent risk behaviors such as substance use. Table 1 displays school and community contextual characteristics and distinctions between the two schools' total student population, including percentage of students receiving free or reduced lunch, percentage of minority students, graduation rate, and median household income in the school community. The researcher obtained written permission from the county Superintendent prior to the start of the study (see Appendix A.) The Internal Review Board (IRB) at West Virginia University also granted permission for the study to occur (see Appendix B).

\section{Participants}

To examine the study's hypotheses, students in grade 12 in two public high schools in North Central West Virginia who had a registered name in the social networking website, Facebook, were invited to participate. Twenty one adolescent males and 29 adolescent females served as participants. Of those participants, 49 , completed the entire survey and served as the basis of this study. Among the total sample, 46 students (95\%) identified themselves as White American; 2 students identified themselves as biracial (American Indian and White American); and the remaining student identified him/herself as African American. In addition, among the total sample, 39 students were 18 years of age while the remaining 10 students were 19 years of age. No students under the age of 18 were able to participate and no student identified themselves as being above the age of 19 . School A had a total of 20 participants ( $40 \%$ of the total sample), while School B included 30 participants $(60 \%$ of the total sample). 


\section{Procedures}

Adolescents in grade 12 at both of the high schools who had a registered Facebook account were invited to participate. The researcher sent students a brief personal invitation (see Appendix C), along with the website URL, asking students to complete the survey. Adolescents were advised in the invitation as well as the first page of the survey that the survey was voluntary and the answers they provided would be kept private. If they were not comfortable answering a question then they could leave it blank. Their grade in the class would not be affected by their decision to participate in the study. Passive consent was assumed by the adolescents through their decision to continue with the survey after reading the introduction page of the survey (see Appendix D).

Participants completed survey questionnaires online using Survey Monkey. Survey Monkey is an easy-to-use tool for the creation and management of online surveys. Through this platform, all study data is stored securely (i.e. password-protected) and is encrypted during data collection and transmission. Students could complete the questionnaire from the privacy of their own home or any other computer of their choosing. The questionnaire was open for students to complete for a total of 27 days. In order to protect subjects' privacy, no identifying information was solicited other than the demographic questions. Again, students were informed that participation in the survey was voluntary and anonymous and would not affect their school grade.

\section{Measures}

The independent variables of the study were classified as individual characteristics, extracurricular activity participation, and school-level characteristics. The dependent variable 
was the level of substance use reported by the adolescents. All variables, with the exception of the school-level characteristics, were assessed using a self-report questionnaire which were administered online using Survey Monkey.

Individual Characteristics. Demographic information from students including birth date, gender, average overall GPA, and ethnicity. Adolescents self-reported their birth date (month/year), gender (male $=1$, female $=2)$; overall GPA $(4.0-3.5=1,3.4-3.0=2,2.9-2.5=3$, 2.4-2.0 = 4, 2.0 or below = 5), and ethnic background (see Appendix C).

School-Based Extracurricular Activity Participation. School-based extracurricular activity participation was measured based on student reports of activity participation at school during the current school year. The school-based extracurricular activity participation survey was partially based on the survey used by Markstrom, Blackshire, and Wilfong (2005). Questions and format were modified to match the activities offered by the target schools and to fit the key variables being examined in this study. Students were asked, "In the current school year, do you (did you) participate in any of the following activities." Students selected which, if any, of 36 school-based extracurricular activities they participated in. These activities were divided in four distinct categories: sports activities (e.g., baseball, basketball, football), performing arts (e.g., art, band, theatre), academic clubs (e.g., BABES, foreign language club, Key Club), and prosocial activities (e.g., Boy scouts, 4-H, volunteer/service work) (see Appendix C). In addition, time commitment for each activity the adolescent indicated he/she participated was assessed. The student was instructed to estimate about how many hours outside of school classes he/she spends each week on the specific activity. For data analysis purposes, a count was produced on the number of activities the adolescent participated in during the current school year. Two 
total counts were produced in order to analyze hypothesis. One count was performed to count the total number of activities the adolescent participated in. The possible range for the total participation count was 0 (indicating no participation in any activities) to 36 (indicating that the adolescent had reported participating in all 36 activities). The other count that was performed to analysis hypothesis 2 was a count on the total number of sports activities the adolescent participated in. The possible range for the sports activities count was 0 (indicating no participation in any sports activities) to 13 (indicating that the adolescent had reported participating in all 13 sports activities.

School and Community-Level Characteristics. At the school level, the following variables were used to judge the role of school characteristics on the relationship between school-based extracurricular activities and substance use: school SES (percentage of students receiving free or reduced lunch), graduation rate, and ethnic composition of each school. Community-level characteristics were defined as the median household income for the community where the school was located. Distinctions of each school are summarized in the following paragraphs and can be seen in Table 1.

The following information was obtained from the West Virginia Report Cards on the Harrison County Board of Education website. This information was based on statistics pertaining to the $2007-2008$ school year. In addition, it is important to mention that according to mapquest.com, these schools are only 6.72 miles away from each other. The populations of these schools in their respective cities share the same recreational activities (e.g., bowling alley, skating rink, parks), shopping centers (e.g., mall, Wal-Mart, Lowes), and entertainment options 
(e.g., cinemas, dining). Therefore, some similarities exist in the larger community resources available to the students, but there are distinctive differences in school SES factors.

In 2007-2008, school A had a total enrollment of 774 students. Of those 774 students, $340(44 \%)$ students received free or reduced lunch. Sixty-one students (8\%) were considered African American (black) or other ethnicity when compared to the rate of students classified as white American (92\%). The reported graduation rate was $74.2 \%$. The reported median household income for the city the school was located in is $\$ 34,377$ (see Table 1).

In 2007-2008, school B had a total enrollment of 863 students. Of those 863 students, $146(17 \%)$ students received free or reduced lunch. Twenty-five students (3\%) were considered African American (black) or another ethnicity when compared to the rate of students classified as white American (97\%). The reported graduation rate was 93.7\%. The reported median household income of the city the school was located in is $\$ 61,148$ (See Table 1 ).

Substance Use. Twenty-four questions pertaining to adolescents' use of tobacco, alcohol, marijuana, and other illicit drugs, which were derived from the 2007 Youth Risk Behavior Survey (YRBS, CDC, 2007), were asked of the adolescents. Using the YRBS, questions related to the present study were used to examine the rate of substance use and abuse. The survey contained eight questions on tobacco use, five questions on alcohol use, three questions on marijuana use, and eight questions on other illicit drug use. The questions measured lifetime abuse, current use, and age of initiation of each substance. However, the present study only analyzed one question about each substance. For the purpose of analyzing cigarette use, the question, "During the past 30 days, on how many days did you smoke cigarettes?" was used. To analyze alcohol use, the question, "During the past 30 days, on how many days did 
you have at least one drink of alcohol?" was analyzed. Also for analyses purposes, marijuana and other illicit drugs were combined into one category, giving the research three types of substances (cigarette, alcohol, and illicit drugs) which were examined separately. Questions pertaining to illicit drug use including questions related to lifetime abuse (i.e. "During your life, how many times have you used marijuana?"). Cigarette and alcohol statistics were measures of the number of days within the last 30 days (0-30) that the adolescent reported using the substance. The possible range on both the alcohol and cigarette use was $0-7$, where 0 indicated that the adolescent had used the alcohol or cigarettes zero days during the past 30 days and 7 indicated that the adolescent had used the alcohol or cigarettes all 30 days during the past 30 days. The possible range on the illicit drug use was $0-7$, where 0 indicated that the adolescent had used the substance zero days during their lifetime and 7 indicated that the adolescent has used the substance 100 or more days during their lifetime (please refer to Appendix D to see what each individual number range was and further explanations).

\section{Analytic Plan}

The Statistical Package for the Social Sciences (SPSS) was used to conduct all analyses. First, preliminary descriptive statistics including means, standard deviations, and range variable were examined for all independent and dependent variables in the study.

In order to examine whether higher rates of involvement in extracurricular activities were associated with lower levels of substance use, bivariate correlations were computed. Correlations were used to examine the relationship between involvement in school-based extracurricular activities and the levels of cigarette, alcohol, and illicit drug use. 
To address the study question of whether males report a greater likelihood of substance use and abuse, especially those involved in sports activities, a hierarchical regression analysis was performed. An interaction between gender and sports activities approached significance. In order to examine the interaction, a post-hoc interaction probing using Soper's (2007) Interaction! Program was executed. All variables were centered before calculating the interaction term used in regression analyses.

Finally, to determine if adolescents from the lower SES school and community (School A) report greater rates of substance use and abuse than those adolescents from the higher SES school and community (School B), an independent sample t-test was implemented. 


\section{Chapter Four}

Results

\section{Preliminary Analyses}

Preliminary analyses included obtaining descriptive statistics, including variable means, standard deviations, and actual range (minimum and maximum values) of all study variables by school and for the full sample (see Table 2).

\section{Hypothesis 1}

The first hypothesis was that higher rates of involvement in school-based extracurricular activities would be associated with lower levels of substance use. Bivariate correlations were computed to assess the relationships between involvement in school-based extracurricular activities and the levels of cigarette, alcohol, and illicit drug use (see Table 3). There was a significant negative correlation between school-based extracurricular activity involvement and cigarette use, $r=.29, p=.05$. High levels of school-based extracurricular activity involvement were associated with low levels of cigarette use, as well as the converse relationship. There was also a significant negative correlation between school-based extracurricular activity involvement and alcohol use, $r=-.29, p<.05$. A high level of school-based extracurricular activity involvement was related to low levels of alcohol use, as well as the converse relationship. A significant correlation was not found for the association between school-based extracurricular activity involvement and illicit drug use, $r=-.13, p>.05$.

\section{Hypothesis 2}

The second hypothesis was that males involved in sports activities would report higher levels of substance use than females. In order to examine this hypothesis, three hierarchical 
multiple regression models were estimated, one for each type of substance use. In each, participant gender was entered on the first step, and level of involvement in sports activities (mean-centered) was entered on the second step. The interaction between gender and sports activities was included on the final step.

Cigarette use. The first step of the regression did not explain a significant portion of the variance in cigarette use, $F(1,47)=.01, p>.05, R^{2}=.00$. Adolescent gender was not associated with number of days participants reported using cigarettes in the past month. At the second step, the addition of sports activities did not explain a significantly greater portion of the variance in cigarette use than was explained by the first step, $\Delta F(1,46)=.73$, $p>.05, \Delta R^{2}=.02$. Neither gender nor involvement in sports activities were associated with cigarette use in the past month. Finally, the addition of the interaction between adolescent gender and sports activities participation did not explain additional variance in cigarette use, $\Delta F(1,45)=.82, p>.05, \Delta R^{2}=.02$. The interaction between gender and sports activities involvement was not a significant predictor of cigarette use.

Alcohol use. The first step of the regression did not explain a significant portion of the variance in alcohol use, $F(1,47)=.78, p>.05, R^{2}=.02$. Adolescent gender was not associated with the number of days that participants reported using alcohol in the past month. At the second step, the addition of sports activities did not explain a significantly greater portion of the variance in alcohol use than was explained by the first step, $\Delta F(1,46)$ $=.67, p>.05, \Delta R^{2}=.01$. Neither gender nor involvement in sports activities were associated with alcohol use in the past month. Finally, the addition of the interaction between 
adolescent gender and sports activities participation approached significance in explaining the variance in alcohol use, $\Delta F(1,45)=4.2, p<.05, \Delta R^{2}=.08$. Using Soper's (2007) Interaction! Program to examine this interaction, a post hoc analysis was conducted. Figure 2 depicts this interaction. Specifically, females who were more involved in sports activities reported the lowest levels of alcohol use; however, males who were highly involved in sports activities reported the most frequent alcohol use. Females who reported low levels of involvement in sports activities reported drinking alcohol as frequently as males at high levels of sports involvement. Low levels of sports involvement for males was associated with moderate alcohol use frequency during the past month.

Illicit Drug Use. The first step of the regression did not explain a significant portion of the variance in illicit drug use, $F(1,47)=1.35, p>.05, R^{2}=.03$. Adolescent gender was not associated with number of times participants reported using illicit drugs in their lifetime. At the second step, the addition of sports activities did not explain a significantly greater portion of the variance in illicit drug use than was explained by the first step, $\Delta F(1,46)=$ $.27, p>.05, \Delta R^{2}=.01$. Neither gender nor involvement in sports activities were associated with lifetime adolescent illicit drug use. Finally, the addition of the interaction between adolescent gender and sports activities participation did not explain additional variance in illicit drug use, $\Delta F(1,45)=.60, p>.05, \Delta R^{2}=.01$. The interaction between gender and sports activities involvement was not a significant predictor of illicit drug use. Hypothesis 3

The third hypothesis was that adolescents from the low SES school would have higher rates of substance use than those adolescents from the high SES school. Three separate 
mean-level comparisons by school were conducted, one for each type of substance use (cigarette, alcohol, and illicit drug use). For cigarette use, this t-test indicated that adolescents from School A ( $M=1.40, S D=1.05)$, were not significantly more likely to use cigarettes than adolescents from School $B(M=1.48, S D=1.12), t(47)=-.26, p>.05$. Similarly, for alcohol use, adolescents in School $A(M=2.10, S D=1.45)$ did not use alcohol more frequently than teenagers in School $B(M=1.93, S D=1.22), t(47)=.41, p>.05$. Finally, for illicit drug use, adolescents in School $\mathrm{A}(M=.70, S D=1.89)$ were no more likely to have used illicit drugs than youth in School B $(M=.20, S D=.77), t(47)=1.262, p>.05$. Overall, no mean differences were found between schools on cigarette, alcohol, and illicit drug use. 
Chapter Five

Discussion

The final chapter of the thesis reiterates the statement of the problem, and briefly reviews the methods employed to conduct the research. The major sections of this chapter summarize research findings and discuss theoretical and practical implications of those findings. Finally, the chapter identifies limitations of the study and makes recommendations in light of the findings.

Research typically indicates that high school students' participation in school-based extracurricular activities yields benefits to the students including higher academic achievement, lower risk of dropout, and, of relevance to this study, lower levels of involvement in deviant behaviors (Eccles et al. 2003; Guest and Schneider, 2003). Nonetheless, there have been discrepancies found in some investigations pertaining to the association of these variables; specifically, certain types of involvement are associated with increased likelihood of involvement in tobacco, alcohol, or drug use. Therefore, the purpose of this study was to fill gaps in previous literature on adolescent involvement in activities that are school-based in relation adolescent alcohol, tobacco, marijuana, and illicit substance use, while taking into account important individual and sociodemographic variables.

Participants in the study were 49 students in 12 th grade from two high schools. All students were either 18 or 19 years old and attended one of the two high schools that are found within the same county. The two high schools were chosen because while the schools are very close in proximity to one another, have a very similar curriculum, and offer the same types of involvement, their school characteristics including number of students receiving free or 
reduced lunch, past graduation rates, and test scores display distinct differences between the two schools. To obtain the data for the school characteristics, the county's board of education website was utilized. In addition, the median household income for School A community was $\$ 34,377$, while the median household income for School B community was $\$ 61,148$. This household income distinction accounted for almost $\$ 27,000$ difference between the two communities.

The present study found statistically significant negative relationships between adolescent substance use and involvement in school-based extracurricular activities. Specifically, students who were involved in school-based extracurricular activities were less likely to use substances, especially cigarettes and alcohol, as well as the converse relationship. The study found no association for gender and involvement in sports activities as predictors of substance use; however, an interaction between gender and involvement in sports approached significance. Finally, there were no significant differences between schools in levels of reported adolescent substance use. These findings comprise the remainder of the discussion in this chapter.

Hypothesis 1

The first hypothesis results yielded a statistically significant negative relationship between adolescent substance use and involvement in school-based extracurricular activities suggests that, in this sample, students who are involved in school-based extracurricular activities are less likely to use substances. The general finding here makes sense and supports previous literature of adolescent substance use. Specifically, it is consistent with the findings of Shilts (1991) who conducted research using the Alcohol and Drug Use Index and found that 
adolescents who did not use alcohol and drugs were highly involved in extracurricular activities. The findings of the current study are also in keeping with those of Leaver-Dunn and colleagues (2007) who found that students involved in sports and other extracurricular activities were less likely to smoke cigarettes, use marijuana, or binge drink.

In Chapter Two, the researcher presented two theoretical frameworks which were used to support the ideas in this research -- Hirschi's (1969/2002) social control theory of delinquency and Bronfrenbrenner's (1986) ecological systems theory. In relation to the first hypothesis, Hirschi's (1969/2002) social control theory of delinquency was examined to support the idea that involvement in extracurricular activities decreases the likelihood that adolescents will use tobacco, alcohol, and illicit drugs. The central idea related to the social control theory was that adolescents who frequently participate in organized activities have less free time to abuse drugs and alcohol. The reverse is that adolescents not involved in organized activities have less structured time with peers and adults and, therefore, have plenty of time to consume alcohol and drugs. This theory was supported in the findings that adolescents who are involved in school-based extracurricular activities are less likely to use substances.

Hypothesis 2

As previously mentioned, the present study found no difference in levels of substance use using gender and involvement in sports activities as predictors for substance use. Interestingly, however, the present study revealed an interaction between gender and sports activities involvement that approached significance. Females who were more involved in sports activities reported less alcohol use, but males who were involved in sports activities reported an increase in alcohol use. Females who reported low levels of involvement in sports activities 
reported drinking alcohol as frequently as males at high levels of sports involvement. Low levels of sports involvement for males was associated with moderate alcohol use frequency during the past month. This finding is similar to Perr-Burney and Takyi (2002) who conducted research on female high school athletes. The findings from their research show that sports participation for females was associated with less alcohol and drug use. Eccles and Barber (1999) found that males who were involved in sports had an increased use of alcohol. This finding is interesting because it demonstrates that involvement in extracurricular activities has different implications for females versus males. It could be assumed that for males, involvement in sports activities is more of a social peer status issue. These boys become known as the jocks of the school and have a relatively high peer status. According to Hoffman (2006), "male athletic participation is often accompanied by a greater propensity to socialize and attend parties where alcohol may be available. Alcohol use is often seen as a rite of passage for adolescent boys who attend after-school or weekend parties" (p. 286). In other words, male athletes may be at greater risk for alcohol use when compared to female athletes given the social oar that comes with being a male athlete. Additionally, in the mainstream society, male sporting events are often accompanied with alcohol and substance use. For example, attending football games, a maledominated sport, has become very publicly associated with alcohol use and is often readily available at games.

Given the lack of research, there is no clear explanation for why female athletes are protected from alcohol use. Perhaps gender roles that support the use of alcohol among males but not among females should be given consideration. Female-dominated sports such as cheerleading and tennis, do not have the social attachment of being an event where alcohol is 
available and a norm. Another possible explanation could be the time constraints required of female athletes. Females could be dedicated to their involvement more and therefore, spend more time outside of classroom time practicing and being involved in the activity. Additionally, female sports are often smaller "team" sports, such as a cheerleading squad of 15 females, when compared to an entire football team comprised of 40 or more males. Therefore, these females may be getting more adult leadership and attention than the male athletes. Finally, females may be protected more from alcohol use because of the attraction to a healthy lifestyle. Females are often involved in sports in order to obtain the health benefits from athletic participation; therefore, if a healthy lifestyle is a priority for female athletes then using alcohol and other substances would put their healthy lifestyle in jeopardy. Still, this interaction failed to account for the significant portion of the variance in alcohol use in this sample. It could be suggested that with a larger sample size, the interaction may account for the significant portion of the variance.

Hypothesis 3

Finally, this study found no significant difference in substance use between the two school samples. It was hypothesized that the adolescents from the low-SES school would report higher rates of substance use than the adolescents from the high-SES. Despite the fact that the hypothesis was not supported, in an extensive review of literature, Hanson and Chen (2007) found similar results. In their study, no significant association was found between SES and alcohol use and marijuana use. Perhaps there are several reasons why no statistically significant relationship and differences were found on the SES variable. First, conceivably, the sample used in this study was too small. That is, there was not sufficient power in the sample 
to detect relationships and differences that might have existed. Accordingly, future studies should consider using larger sample sizes. Secondly, this finding could also be a result of methodological flaws; namely, the method of recruitment and ability for adolescents to complete the survey. It could be possible that some adolescents who fall in the extremely lowSES populations do not have access to computers which prevented their participation. Therefore, it could be speculated that adolescents who completed the survey may not have been representative of the population of the schools in terms of SES. Relationships and differences were not detected because the sample was too homogeneous or too similar and not representative of youth as a whole. It may also be speculated that the reason for finding no significant association between SES and alcohol and marijuana use is that during adolescence, the influence of peer's and the social standing of the adolescent amongst his/her school and peers are more influential as opposed to family SES (Hanson \& Chen, 2007). It is also important to note that the present study did not examine individual family SES, which is a recommendation for future research. This study aimed to explore school-level contextualcharacteristics, including school SES (utilizing the ratio of students receiving free or reduced lunch) and community SES (median household income), to identify the adolescents who would be at risk for low SES.

In the current study's review of literature, hypothesis two and three were based on Bronfrenbrenner's theory which suggests that the adolescent's surroundings including his/her home, school, work, peers, community, church etc. will all have an influence on the way an adolescent develops and his/her proclivity to engage in substance use. Accordingly, hypothesis two examined the effects of gender. Most studies have found that a greater number of males 
abused alcohol and other drugs than females (Leaver-Dunn, Turner, \& Newman, 2007;

O'Malley, Johnston, \& Bachman, 1998). However, in the present study sample, this was not the case. This discrepancy, nonetheless, is frequently observed in the literature. Hoffman (2006) found no difference in alcohol use between male versus female school athletes. As was seen in the interaction of gender and sports activities involvement, in this sample, females who reported low levels of involvement in sports activities reported drinking alcohol as frequently as males at high levels of sports involvement. Hence, it is not a simple matter of males versus females, but rather distinct involvement in different types of activities. It could be possible that this distinction is a result of fewer opportunities for females to be involved in sports activities. High school sports activities are generally male-dominated and boy's teams are more highly publicized and find more prestigious than girls teams. The task for future research is to explore this distinct activity and gender differences and interactions to determine the different meanings that extracurricular activities hold among male and female adolescents.

In addition, Bronfrenbrenner's theory was used as a basis to develop hypothesis three. The hypothesis that adolescents from the low-SES school would report higher rates of substance use than those from the high-SES school was developed from the notion that the community and school could act as a risk factor or a protective factor for adolescent substance use. Poor community quality has been linked to substance abuse (Brewster et al, 1993; Roche et al, 2005). In this sample, this claim was not supported, as results demonstrated no significant difference in reported rates of substance use between the two schools. The present study attempted to only examine one system of Bronfrenbrenner's ecological system- the microsystem. It is suggested for future research to examine the effects of all parts of the 
system-- the microsystem, mesosystem, exosystem, and macrosystem. It could be that it is the interaction of more than one or all of these systems that could affect the rates of adolescent substance use. The central argument relative to the school contextual characteristics was that the students in the low-SES school have been exposed to more substance use, by both their peers and family because researchers have found that, among adults, lower SES is associated with higher substance use (Adler et al., 1994; Lantz et al., 2001). However, it could be possible that although these two schools differ in their community median income, school SES, and graduation rate that the short distance between the two schools minimized any significant effects that these characteristics could produce. In other words, students from both of the schools have friends at the opposite school, they attend the same community social functions, and share the same entertainment sources. It is recommended for future research to examine schools that are not associated with one another and are of a further distance away to truly determine the effects of community and school characteristics.

On the one hand, these findings offered some knowledge and insight into things previously not available in the literature and, on the other hand, this new knowledge provided new directions for further discovery. The new directions are presented in the form of recommended research that is discussed later in this chapter. But first, based on what is known from the present study, following is a discussion of the implications of the research findings. Nonetheless, it must be noted that these ideas are speculative given the small sample size of the study to make meaningful comparisons between the two schools. 
Implications of Research Findings

In Chapter One, it was argued that this specific investigation was necessary in order to "narrow the gap" in existing literature on the variables examined. Accordingly, efforts are made to do so by discussing the implications of the current research findings. The following discussion restates the findings of the investigation and then talks about the implications of those findings.

This study found a statistically significant negative relationship between involvement in school-based extracurricular activities and substance use which suggests that students who are involved in school-based extracurricular activities tend to be somewhat protected from substance use. The practical implication of this finding is that students benefit from involvement in school-based extracurricular activities, unless males are participating in sports activities. Accordingly, educators, parents, communities, and counselors should look for ways to encourage students to get involved in the activities that their school has to offer. It also implies that school and communities should make activities for adolescents available. If schools offer limited sports and clubs for their students to be actively involved in, then they may be putting these adolescents at risk for substance use. The family can also play an important role in encouraging the adolescent to get involved in extra-curricular activities in the school and community. If the family does not support the adolescent then the adolescent will likely not be an active participant in activities. The school, community, and family must work together to promote a healthy environment for the teenager.

With respect to the findings that gender and sports activities involvement did not predict substance use, practical implication of these findings is that involvement in any type of 
activities, with the exception of male participation in sports activities, could be used to protect adolescent from substance use. However, it would be of interest and recommended for future research to look at the association of substance use relative to the amount of time the adolescent spends being involved in the activity and other individual and sociodemographic characteristics. This could provide more explanation and understanding pertaining to whether it is the actual activity, perhaps the peers and adult role models that is protecting the adolescent, or whether or not it is the concept that because the adolescent does not have spare time to engage in deviant behaviors that is protecting the adolescent from substance use. It seems plausible to assume that sports activities require more time use than involvement in a school club. Future research should also look at the degree of influence of each activity. For the present study, it can only be concluded that it appears that any type of involvement may be helpful in protecting adolescents from substance use.

Another aim of the present study was its consideration of school-context effects. Research points to the many discrepancies between schools in their ability to offer beneficial activities to students (Guest \& Schneider, 2003) as well as the financial ability to participate in activities. Those students who come from an area of low socioeconomic status may not have the finances available to participate in some of these activities that are relatively very costly, including the expense of transportation to activities and uniforms and safety gear. It was hypothesized that adolescents from the low-SES school would report more substance use than adolescents from the high-SES school. However, this study found no statistically significant difference between schools in relation to substance use. This finding implies that all youth have equal opportunity to engage in activities. Despite SES, if the activities are available, then both 
high SES and low SES adolescents should have the same opportunities and availability of activities to be actively involved in. Researchers need to learn to what extent nonparticipation is influenced by family responsibilities or economic pressures, personal preferences, social discomfort, or other factors, and whether some of these barriers can be overcome. This research took one step towards examining these familial influences.

The aforementioned implications of the findings of this research study have been provided as a way of interpreting the results so as to meaningfully narrow the gap in existing literature. Despite the efforts of this investigation, more research needs to be conducted to address lingering questions. Future research is needed due to the limitations of the present study and in the broader field of adolescent substance use and abuse. Some limitations of the present study are discussed next.

\section{Limitations and Conclusions}

There are several limitations to this research that make its conclusions uncertain. First, like all cross-sectional correlational research where the objective is to examine relationships at one point of time, this study examined the associations between involvement in school-based extracurricular activities (sports teams, performing arts activities, community-based activities, and academic clubs) and tobacco, alcohol, and illicit drug use and abuse. Due to correlational findings, this study cannot and does not say whether or not one variable influences or affects another, nor can it or does it say if there is an influence or an effect, to what degree that influence or effect exists. The only thing the findings can imply is whether or not a relationship exists between these variables. Using cross-sectional data also only allows the research to find that adolescents who are currently involved in school-based extracurricular activities are 
currently related to lower levels of reported substance use. It does not allow an examination the long-term effects that involvement in extracurricular activities could have on adolescents.

Secondly, this study is limited in its generalizability and methodology. This study was primarily comprised of White students in one county in the state of West Virginia. The results, therefore, cannot be applied to populations that are of a different composition, such as middle school students in urban settings or high school students in settings with more ethnic diversity. Future studies are needed with nationally representative samples suited to address ethnic and cultural differences in tobacco, alcohol, and drug use. In addition, the sample in this study is a very elite portion of the school population. The present study only sampled those students who were in the 12th grade and near high school graduation. Therefore, students who are or were highly involved in heavy substance use may have been at greater risk for drop-out and may not be represented in this graduating group of seniors. If the study had sampled students in other grades, then students who were struggling and were at the greatest risk of becoming a high-school dropout could have been sampled. However, due to the sampling strategy, only those students 18 or older in the 12 th grade at the schools were targeted for the present study.

The third and possibly most limiting factor of this research is the small sample size. Given financial barriers and time constraints of the present study, the research was conducted through the internet site, SurveyMonkey, instead of a paper-and-pencil study conducted in the schools. Only students in one grade were invited to participate so that parental consent forms would not have to be obtained. As such, the results of the study should be read with the understanding that same results could possibly have been different if the study included more participants. It can be speculated that significance would have been found, especially 
pertaining to the gender and sports activities involvement interaction, if the sample size had been larger.

Fourth, because responses to the survey were obtained through an internet survey, results could differ if responses were collected in the school setting, as has been the standard procedure used when giving the YRBS. The method of recruitment involved only those adolescents who were currently registered on the popular social networking website Facebook. This was the only recruitment method used in the present study which limits those students who do not have access to computers or may simply not be interested in the social networking website. It could be possible that some adolescents who fall in the extremely low-SES populations do not have access to computers which prevented their participation. Therefore, it could be speculated that adolescents who completed the survey may not have been representative of the population of the schools in terms of SES. On the converse, because the survey was given through the internet at the adolescents own time, and not during the school setting where adolescents are already at school, the sample could be limited due to the time constraint of completing the survey. Those students who are highly involved in school activities and are the class leaders may not have the time to engage in social networking such as Facebook. Therefore, they were not given the opportunity to complete the survey. Even if they had a registered Facebook account, these students who are highly involved in school activities may not have logged on to their account during the 27 days that the survey was available and/or they may have chosen not to take the time to complete the survey. Completing the survey at the school during regular scheduled class time would allow the opportunity for all 
students, those who are highly involved and those who are not involved or do not have access to a computer, to complete the survey if they wished.

Despite its limitations, the study adds to the literature documenting the importance of involvement in extracurricular activity for adolescents. These limitations are offered as a proposal to guide future research. While many gaps and questions remain pertaining to the effects that involvement in extracurricular activities could have on adolescents, the present study adds to the wealth of research demonstrated the positive effects that involvement in extracurricular activities, specifically focusing on the negative association of substance use. The present study was conducted in hopes of contributing to the research to help researchers, schools, and communities to identify alternatives to substance use that may protect adolescents. 


\section{References}

Adler, N. E., Boyce, T., Chesney, M. A., Cohen, S., Folkman, S., Kahn, R. L. et al. (1994). Socioeconomic status and health. American Psychologist, 49, 15-24.

American Psychiatric Association. (1994). Diagnostic and statistical manual of mental disorders (4th ed.). Washington, DC

Barnes, G., Hoffman, J., Welte, J., Farrell, M., \& Dintcheff, B. (2007). Adolescents' time use: Effects on substance use, delinquency and sexual activity. Journal of Youth \& Adolescence, 36, 697-710.

Beman, D. (1995). Risk factors leading to adolescent substance abuse. Adolescence, 30(117), 201-208

Berk, L. E. (2007). Development through the lifespan (4th ed.). Boston, MA: Allyn \& Bacon. Borden, L., Donnermeyer, J., \& Scheer, S. (2001). The influence of extra-curricular activities and peer influence on substance use. Adolescent \& Family Health, 2, 12-19.

Boyd, D., \& Bee, H. (2006). Lifespan development, 4th ed. Auckland New Zealand: Pearson Education New Zealand.

Bradley, R.H., \& Corwyn, R.F. (2002). Socioeconomic status and child development. Annual Review of Psychology. 53, 379-399.

Bradley, R.H., Whiteside-Mansell, L.(1997). Children in poverty. In Handbook of Prevention and Treatment With Children and Adolescents, et. RT Ammerman, M Hersen, pp. 13-58. New York: Wiley 
Brewster, K.L., Billy, J.O., \& Grady, W.R. (1993). Social context and adolescent behavior: The impact of community on the transition to sexual activity. Social Forces, 71, 713-740.

Bronfenbrenner, U. (1986). Ecology of the family as a context for human development: Research perspectives. Developmental Psychology, 22, 723-42.

Bronfenbrenner, U., \& Morris, P. (1998). The ecology of developmental processes. Handbook of child psychology: Volume 1: Theorectical models of human development (5th ed.) (pp. 993-1028). Hoboken, NJ: John Wiley \& Sons Inc.

Callen, K. (1985). Teen drug use patterns reviewed. Journal of Child and Adolescent Psychotherapy, 2, 303-304.

Centers for Disease Control and Prevention. 2007 Youth Risk Behavior Survey. Available at: www.cdc.gov/yrbss. Accessed on September 12, 2008.

Cooley, V. E., Henriksen, L. W., Van Nelson, C., \& Thompson, J. C., Jr. (1995). A study to determine the effect of extracurricular participation on student alcohol and drug use in secondary schools. Journal of Alcohol and Drug Education, 40, 71-87.

Cottrell, S., Branstetter, S., Cottrell, L., Harris, C., Rishel, C., \& Stanton, B. (2007). Development and Validation of a Parental Monitoring Instrument: Measuring How Parents Monitor Adolescents' Activities and Risk Behaviors. Family Journal, 15, 328-335.

Crosby, R. A., DiClemente, R. J., Wingood, G. M., Sionean, C., Cobb, B., \& Harrington, K. (2000). Correlates of unprotected vaginal sex among African American female teens: The importance of relationship dynamics. Archives of Pediatrics and Adolescent Medicine, 754, 893-899. 
Crosnoe, R. (2002). Academic and health-related trajectories in adolescence: The intersection of gender and athletics. Journal of Health \& Social Behavior, 43, 317-335.

Darling, N. (2005). Participation in Extracurricular Activities and Adolescent Adjustment: Cross-Sectional and Longitudinal Findings. Journal of Youth \& Adolescence, 34, 493-505.

D'Amico, E. J., McCarthy, D. M. (2006). Escalation and Initiation of Younger Adolescents' Substance Use: The Impact of Perceived Peer Use. Journal of Adolescent Health, 39, 481-487.

DiClemente, R. J., Wingood, G. M., Crosby, R. A., Cobb, B. K., Harrington, K., Davies S., Hook, E. W., \& Oh, M. K. (2001). Parental monitoring and its association with a spectrum of adolescent health risk behaviors. Pediatrics, 107, 1363-1368.

Eccles, J.S., \& Barber, B.L. (1999). Student council, volunteering, basketball, or marching band: What kind of extracurricular involvement matters? Journal of Adolescent Research, 14, $10-43$

Eccles, J. S., Barber, B. L., Stone, M. R., \& Hunt, J. (2003). Extracurricular activities and adolescent development. Journal of Social Issues, 59, 865-889.

Feldman, A., \& Matjasko, J. (2005). The Role of School-Based Extracurricular Activities in Adolescent Development: A Comprehensive Review and Future Directions. Review of Educational Research, 75, 159-210.

Goodman, E. (1999). The role of socioeconomic status gradients in explaining differences in adolescents' health. American Journal of Public Health, 89, 1522-28. 
Guest, A. \& Schneider, B. (2003). Adolescents' extracurricular participation in context: The mediating effects of schools, communities, and identity. Sociology of Education, 76, 89109.

Hanson, M. D., \& Chen, E. (2007). Socioeconomic status and substance use behaviors in adolescents: The role of family resources versus family social status. Journal of Health Psychology, 12(1), 32-35.

Harnett, R., Thorn, B., Herring, R., Kelly, M. (2000). Alcohol in transition: Towards a model of young men's drinking styles. Journal of Youth Studies, 3, 61-77.

Harrison, P. \& Narayan, G. (2003). Differences in Behavior, Psychological Factors, and Environmental Factors Associated with Participation in School Sports and Other Activities in Adolescence. Journal of School Health, 73, 113.

Hirschi, T. (1969/2002). Causes of Delinquency. Originally published in 1969 by University of California Press. 2002 edition with a new introduction by the author. Transaction Publishers, New Brunswick, NJ.

Hoffmann, J. (2006). Extracurricular Activities, Athletic Participation, and Adolescent Alcohol Use: Gender-Differentiated and School-Contextual Effects. Journal of Health \& Social Behavior, 47, 275-290.

Hoffmann, J., \& Xu, J. (2002). School Activities, Community Service, and Delinquency. Crime \& Delinquency, 48, 568.

Jeynes, W. (2002). The relationship between the consumption of various drugs by adolescents and their academic achievement. American Journal of Drug and Alcohol Abuse, 28, 15-35. 
Kohr, Colderon, Skiffington, Masters, \& Blust. (1988). The influence of race, class, and gender on self-esteem for fifth-eighth-and eleventh-grade students in Pennsylvania schools. Journal of Negra Education, 57, 467-81.

Kostelecky, K. (2005). Parental attachment, academic achievement, life events and their relationship to alcohol and drug use during adolescence. Journal of Adolescence, $28,665-669$.

Lantz, P. M., Lynch, J. W., House, J. S., Lepkowski, J. M., Mero, R. P., Musick, M. A. et al (2001). Socioeconomic disparities in health change in a longitudinal study of US adults: The role of health-risk behaviors. Social Science \& Medicine, 53, 29-40.

Leaver-Dunn, D., Turner, L., \& Newman, B. (2007). Influence of sports' programs and club activities on alcohol use intentions and behaviors among adolescent males. Journal of Alcohol and Drug Education, 51.

Leventhal, T. \& Brooks-Gunn, J. (2000). The neighborhoods they live in: The effect of neighborhood residence on child and adolescent outcomes. Psychological Bulletin, 126, 309-337.

Lindström, M., Merlo, J., \& Östergren, P. (2002). Individual and neighborhood determinants of social participation and social capital: a multilevel analysis of the city of Malmö, Sweden. Social Science \& Medicine, 54, 1779.

Lohman, B., \& Billings, A. (2008). Protective and risk factors associated with adolescent boys' early sexual debut and risky sexual behaviors. Journal of Youth \& Adolescence, 37, 723-735. 
Lorente, F. O., Peretti-Watel, P., Griffet, J., \& Grelot, L. (2003). Alcohol use and intoxication in sport university students. Alcohol and Alcoholism, 38, 427-430.

Luthar, S. S., \& Becker, B. E. (2002). Privileged by pressured? A study of affluent youth. Child Development, 73, 1593-1610.

Luthar, S. S., \& Latendresse, S. J. (2005). Children of the affluent: Challenges to well-being. Psychosomatic Medicine, 14, 49-53.

Mahoney, J. L. (2000). School extracurricular activity participation as a moderator in the development of antisocial patterns. Child Development, 71, 502-516.

Mahoney, J. \& Cairns, R. (1997). Do extracurricular activities protect against early school dropout?. Developmental Psychology, 33, 241.

Mahoney, J., Cairns, B., \& Farmer, T. (2003). Promoting interpersonal competence and educational success through extracurricular activity participation. Journal of Educational Psychology, 95, 409.

Markstrom, C., Li, X., Blackshire, S., \& Wilfong, J. (2005). Ego strength development of adolescents involved in adult-sponsored structured activities. Journal of Youth \& Adolescence, 34, 85-95.

Marsh, H., \& Kleitman, S. (2002). Extracurricular school activities: The good, the bad, and the nonlinear. Harvard Educational Review, 72, 464-514.

O’Malley, P., Johnston, L., \& Bachman, J. (1998). Alcohol use among adolescents. Alcohol Health \& Research World, 22, 85. 
Parker, J., \& Benson, M. (2004). Parent-adolescent relations and adolescent functioning: Self-esteem, substance abuse, and delinquency. Adolescence San Diego, 39, 155.

Paquette, D. and Ryan, J. (2001). Bronfenbrenner's ecological systems theory.

Pearlman, M. (1995). The role of socioeconomic status in adolescent literature. Adolescence, 30, 223.

Pearson, M., Sweeting, H., West, P., Young, R., Gordon, J., \& Turner, K. (2006). Adolescent substance use in different social and peer contexts: A social network analysis. Drugs: Education, Prevention \& Policy, 13, 519-536.

Perry-Burney, G., \& Takyi, B. (2002). Self esteem, academic achievement, and moral development among adolescent girls. Journal of Human Behavior in the Social Environment, 5, 15-27.

Rao, U. (2001). Depression and substance use disorders in adolescents. PREVENTION RESEARCHER, 8(4), 15-16.

Resnick, M. D., Bearman, P. S., Blum, R. W., Bauman, K. E., Harris, K. M., Jones, J., Tabor, J., Beuhring, T., Sieving, R. E., Shew, M., Ireland, M., Bearinger, L., Udry, J. R. (1997). Protecting adolescents from harm. JAMA: Journal of the American Medical Association, $278,823$.

Richman, C. et al. (1985). General and specific self-esteem in late adolescent students: Race + gender + ses effects. Adolescence, 20, 555-66. 
Roche, K. M., Mekos, D., Alexander, C. S., Astone, N. M., Bandeen-Roche, K., Ensminger, M. E. (2005). Parenting influences on early sex initiation among adolescents: How neighborhood matters, Journal of Family Issues, 26, 32-34.

Santrock, J.W. (2007). Adolescence (12th ed.). Boston: McGraw Hill.

Shilts, L. (1991). The relationship of early adolescent substance use to extracurricular activities, peer influence, and personal attitudes. Adolescence, 26, 613-617.

Shonkoff J. P., Phillips D. A., (2000). From Neurons to Neighborhoods: The Science of Early Childhood Development. Washington, DC: National Academic Press

Soper, D. S. (2007). Interaction! [Statistical calculator]. Downloaded November 4, 2008, at http://www.danielsoper.com/Interaction/

Trieber, R., Harshfield, G., Davis, H., Kapuku, G., \& Moore, D. (1999) Stress responsivity and body fatness: links between socioeconomic status and cardiovascular risk factors in youth. See Adler et al. pp. 435.38 .

Van der Vorst, H., Engels, R., Meeus, W., \& Dekovic, M. (2006). Parental attachment, parental control, and early development of alcohol use: A longitudinal study. Psychology of Addictive Behaviors, 20, 107-116.

Voisin, D. R. (2003). Victims of community violence and HIV sexual risk behaviors among urban African American adolescent males. Journal of HIV/AIDS Prevention and Education for Adolescents \& Children, 5(3/4), 87-110.

Voisin, D., DiClemente, R., Salazar, L., Crosby, R., \& L., W. (2006). Ecological Factors Associated with STD Risk Behaviors among Detained Female Adolescents. Social Work, 51, 71-79. 
Wagner, F. A., Anthony, J. C. (2002). Into the world of illegal drug use: Exposure opportunity and other mechanisms linking the use of alcohol, tobacco, marijuana, and cocaine. American Journal of Epidemiology, 155, 918-925.

Walsh, A. (1995). Parental attachment, drug use, and facultative sexual strategies. Social Biology, 42, 95-107.

West, P., Sweeting, H., \& Leyland, A. (2004). School effects on pupils' health behaviours: evidence in support of the health promoting school. Research Papers in Education, 19, 261- 291.

Wills, T. A., McNamara, G., Vaccaro, D. (1995). Parental education related to adolescent stresscoping and substance abuse: development of a meditational model. Health Psychology, 14, 464-78.

Wilson, N., Syme, S., Boyce, W., Battistich, V., \& Selvin, S. (2005). Adolescent alcohol, tobacco, and marijuana use: the influence of neighborhood disorder and hope. American Journal of Health Promotion, 20, 11-19.

Zill, N., Nord, C. W., \& Loomis, L. S. (1995). Adolescent time use, risky behavior, and outcomes: An analysis of national data. Rockville, MD: Westat. 
Table 1

School-level Characteristics

\begin{tabular}{llll}
\hline \multicolumn{4}{c}{ School-level Characteristics } \\
& School A & School B & Total \\
\cline { 2 - 4 } Enrollment & 774 & 863 & 1637 \\
\% of Students receiving free or reduced lunch & $44 \%$ & $17 \%$ & $30 \%$ \\
\% of Minority students & $8 \%$ & $3 \%$ & $5 \%$ \\
Graduation rate \% & $74.2 \%$ & $93.7 \%$ & \\
City median household income & $\$ 34,377$ & $\$ 61,148$ & \\
\hline
\end{tabular}

Table 2

Study Variable Descriptive Statistics by School and Full Sample

\begin{tabular}{lcccccc}
\hline & \multicolumn{2}{c}{ School A $(N=20)$} & \multicolumn{2}{c}{ School B $(N=30)$} & \multicolumn{2}{c}{ Full Sample } \\
\hline Variable & M (SD) & Range & M (SD) & Range & M (SD) & Range \\
Cigarette Use & $1.45(1.05)$ & $0-5$ & $1.48(1.10)$ & $0-5$ & $1.45(1.10)$ & $0-5$ \\
Alcohol Use & $2.10(1.45)$ & $0-5$ & $1.93(1.22)$ & $0-5$ & $2.00(1.30)$ & $0-5$ \\
Illicit Drug Use & $.70(1.89)$ & $0-7$ & $.21(.77)$ & $0-5$ & $.41(1.35)$ & $0-7$ \\
Sports Activities Involvement & $.95(1.23)$ & $0-4$ & $.55(.95)$ & $0-3$ & $.71(1.08)$ & $0-4$ \\
Overall Involvement & $4.50(4.07)$ & $0-14$ & $3.90(2.70)$ & $0-10$ & $4.14(3.30)$ & $0-14$ \\
\end{tabular}


Table 3

Bivariate Correlations for School-Based Involvement with Cigarette, Alcohol, and Illicit Drug Use

\begin{tabular}{lcccc}
\hline & 1 & 2 & 3 & 4 \\
\hline 1. Cigarette Use & -- & $.56^{* *}$ & $.66^{* *}$ & $-.29^{*}$ \\
2. Alcohol Use & -- & -- & $.53^{* *}$ & $-.29^{*}$ \\
3. Illicit Drug Use & -- & -- & -.13 \\
4. Extracurricular Involvement & & & & \\
\end{tabular}

Note. ${ }^{*} p<.05,{ }^{* *} p<.01$ (two-tailed). 
Table 4

Summary of Hierarchical Regression Analyses for Variables Predicting Cigarette, Alcohol, and Illicit Drug Use $(N=48)$

\begin{tabular}{|c|c|c|c|c|c|c|c|c|c|}
\hline \multirow[b]{2}{*}{ Variable } & \multicolumn{3}{|c|}{ Cigarette Use } & \multicolumn{3}{|c|}{ Alcohol Use } & \multicolumn{3}{|c|}{ Illicit Drug Use } \\
\hline & $B$ & $S E B$ & $\beta$ & $B$ & $S E B$ & $\beta$ & $B$ & SE B & $\beta$ \\
\hline \multicolumn{10}{|l|}{ Step 1} \\
\hline Gender & -.04 & .32 & -.02 & .33 & .38 & .13 & .45 & .39 & .17 \\
\hline$R^{2}$ & & .00 & & & .02 & & & .03 & \\
\hline \multicolumn{10}{|l|}{ Step 2} \\
\hline Gender & .09 & .35 & .04 & .19 & .42 & .07 & .36 & .43 & .13 \\
\hline Sports Activities & -.14 & .16 & -.14 & .16 & .19 & .13 & .10 & .20 & .08 \\
\hline$R^{2}$ & & .02 & & & .03 & & & .03 & \\
\hline$\Delta R^{2}$ & & .02 & & & .01 & & & .01 & \\
\hline \multicolumn{10}{|l|}{ Step 3} \\
\hline Gender & .16 & .36 & .07 & .37 & .41 & .14 & .43 & .45 & .16 \\
\hline Sports Activities & -.41 & .35 & -.41 & -.57 & .40 & .40 & -.19 & .43 & -.15 \\
\hline Gender* Sports activities & .35 & .39 & .30 & .93 & .4 & .45 & .38 & .49 & .25 \\
\hline$R^{2}$ & & .03 & & & .01 & & & .05 & \\
\hline$\Delta R^{2}$ & & .02 & & & .08 & & & .01 & \\
\hline
\end{tabular}

Note. Sports activities was mean-centered. ${ }^{*} p<.05$. 
Table 5

Cigarette, Alcohol, and Illicit Drug Use Means for School A (Low SES) and School B (High SES)

\begin{tabular}{lcccc}
\hline & \multicolumn{2}{c}{$M(S D)$} & & \\
\cline { 2 - 4 } & School A & School B & $t$ & df \\
\hline Cigarette Use & $1.40(1.05)$ & $1.48(1.12)$ & -.26 & 47 \\
Alcohol Use & $2.10(1.45)$ & $1.93(1.22)$ & .41 & 47 \\
Illicit Drug Use & $.70(1.89)$ & $.20(.77)$ & 1.26 &
\end{tabular}

Note. ${ }^{*}=p<.05$ 


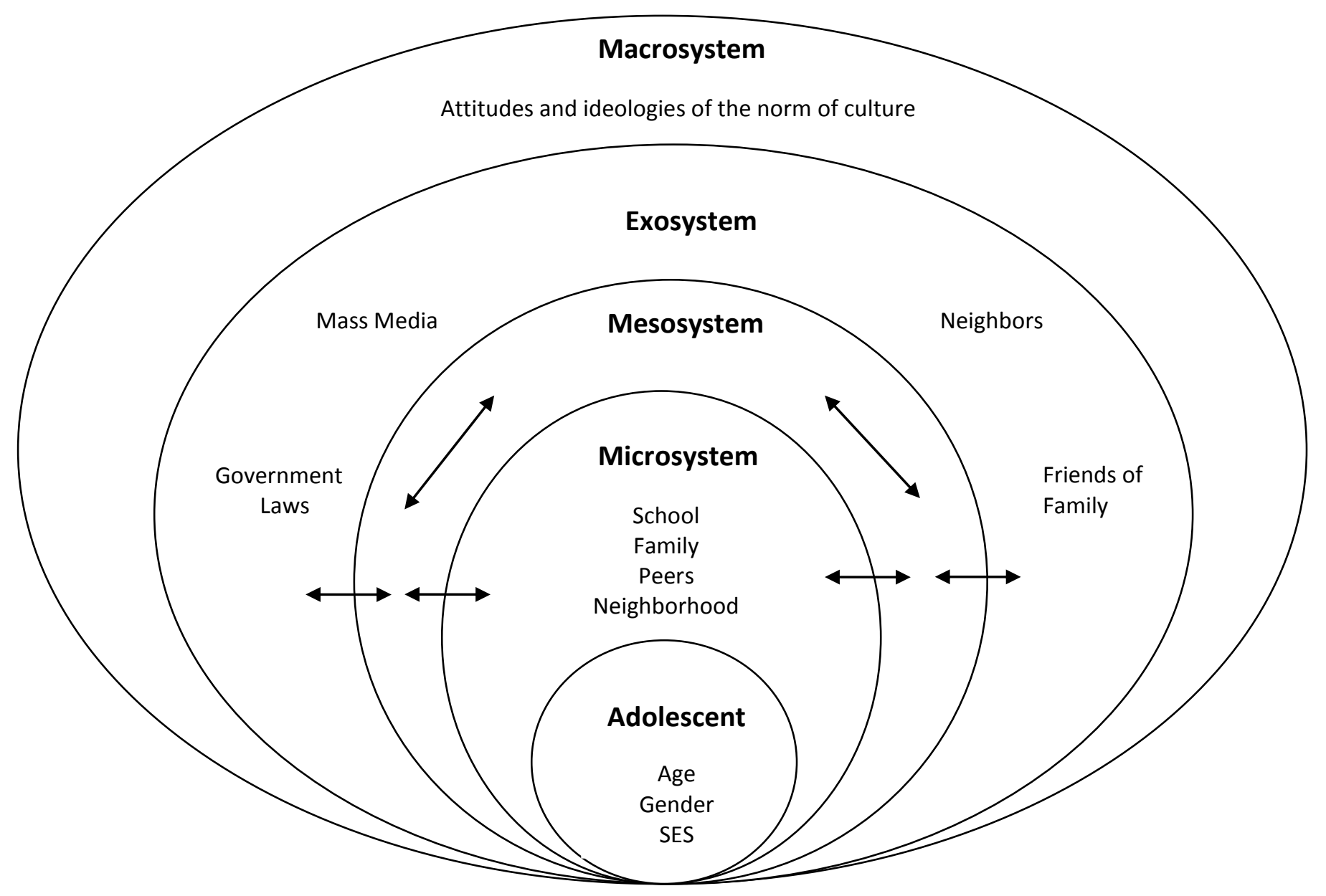

Figure 1- Ecological Systems Model based off of Bronfenbrenner's theory (1986) 
Figure 2

Post hoc analysis interaction

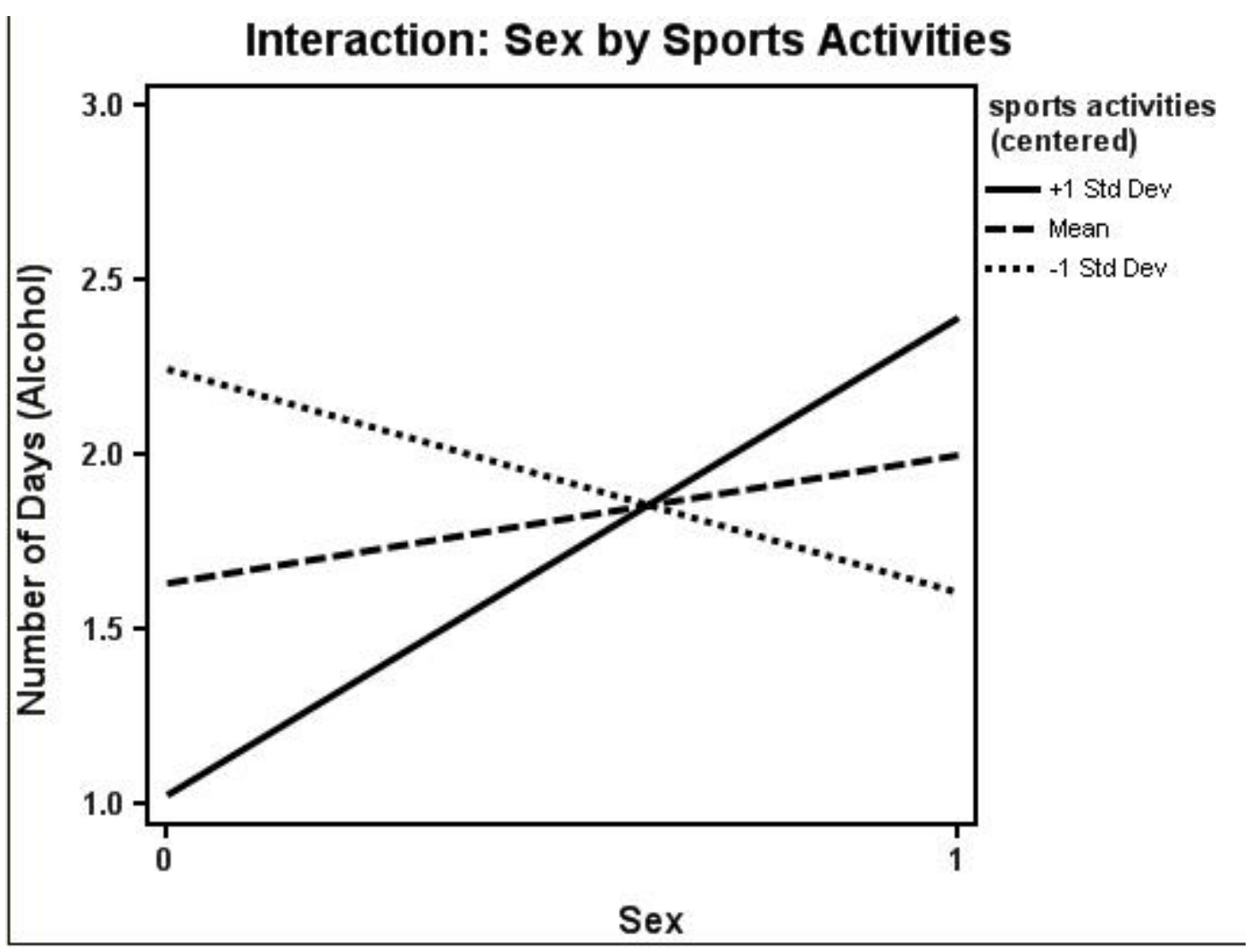




\section{Appendix A}


Dear Ms. Maxwell:

Thank you for your letrer of March 29, 2009, in which you requested permission to conduct research at high schools for your Masters thesis. From the descriprion in your letter, I understand this to be a totally anonymous study to include a sample demographic survey, a substance use survey, and an extra-curricular activities participation survey.

I have also reviewed the survey instruments to be used in your study which you mailed to me. I understand that parents and students will be required to sign a consent form to participate.

One assurance required of all who are permitted to conduct research projects in our county is that a copy of your results be forwarded to this office upon completion of your study.

Given the sbove, and your agreement to provide a summary of results, I am happy to grant permission for your research project to be conducted in the two (2) schools requested. Please feel free to contact those high school principals who will facilitate your project.

Please be advised, however, that County Schools reserves the option to, at any time, rescind permission to conduct your project should it change significantly from it original stated purpose. Also, participation in your research project is at the discretion of the principal and teachers at the school.

Best wishes for success in completing your dissertation.

Sincerely, 


\section{Appendix B}




\title{
W. West VirginiaUniversity.
}

Office of Research Compliance

\section{Expedited-IRB Protocol-Exemption}

\author{
To: Markstrom, Carol \\ From: $\quad$ WVU Office of Research Compliance \\ Date: $\quad$ Wednesday, May 06, 2009 \\ Subject: Exemption Acknowledgement \\ Tracking \#: H-21668 \\ Title: $\quad$ Adolescent Substance Use and Abuse: The Association with \\ Participation in Adult-Structured School-Based Activities and \\ Individual and School-Level Characteristics
}

The above-referenced study was reviewed by the West Virginia University Institutional Review Board (IRB) and was granted exemption in accordance with 45 CFR 46.101(2).

This protocol was reviewed using the following:

Exemption Checklist (210r)

This research study was granted an exemption in accordance with Research that involves educational tests, survey procedures, interview procedures or observation of public behavior [45 CFR 46.101(2)].

The following documents have been acknowledged for use in this study and are available in the BRAAN system:

Cover Letter

Thank you.

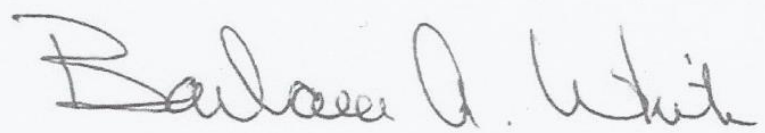

Board Designee: White, Barbara

Letter Sent By: White, Barbara, 5/5/2009 9:46 AM 
Appendix C 
Invitation to Participation

My name is Kari Maxwell; I was a 2003 RCB graduate. I am asking for your help and involvement in my final project which will allow me to graduate with my Master's degree in Child Development and Family Studies at WVU. You are being asked to participate in a short questionnaire about the relationship of alcohol, tobacco, and drug use and involvement in extracurricular activities. If you complete the survey, which should only take you 10 minutes, you will be entered to win 1 of 8 \$25 WalMart gift cards! The survey is completely anonymous and very easy to do. All if you have to do is go to this website: www.SurveyMonkey.com/wvact More information concerning the questionnaire is available on the first page- Please check it out! You will only have until Friday, May 22 to complete the questionnaire. Don't forget to complete the whole questionnaire to be entered into the WalMart gift card drawing! Please feel free to message me back or email me at kstewa14@mix.wvu.edu with any questions or problems.

Thanks, Kari 


\section{Dear Participant,}

This letter is a request for you to take part in a research project to examine the relationship between involvement in extracurricular activities and adolescent alcohol, tobacco and substance use. This project is being conducted by Kari Maxwell, B.A. for a Master's Degree in Child Development and Family Studies in the Department of Technology, Learning, and Culture at WVU with supervision of Dr. Carol Markstrom, a full professor in the College of Human Resources and Education. Your participation in this project is greatly appreciated and will take approximately 20 minutes to fill out the questionnaire.

Your involvement in this project will be kept as confidential as legally possible. All data will be reported in the aggregate. You must be 18 years of age or older to participate. I will not ask any information that should lead back to your identity as a participant. Your participation is completely voluntary. You may skip any question that you do not wish to answer and you may discontinue at any time. Your school class standing will not be affected if you decide either not to participate or to withdraw. West Virginia University's Institutional Review Board acknowledgement of this project is on file.

In order to participate all you need to do is go to the following weblink:

www.surveymonkey.com/wvact At completion of the survey questions, you will be directed to another link which you can enter your name and email address to be entered into a drawing to win one of eight \$25 WalMart gift cards.

I hope that you will participate in this research project, as it could be beneficial to researchers, schools, and communities to identify alternatives to substance use that may protect teens. Thank you very much for your time. Should you have any questions about this letter or the research project, please feel free to contact Kari Maxwell at (304) 669-7517 or by e-mail at kstewa14@mix.wvu.edu.

Thank you for your time and help with this project.

Sincerely,

Kari Maxwell, B.A.

Dr. Carol Markstrom, Ph.D. 


\section{Demographic}

Section 1 of this survey is a simple demography survey. The questions that ask about your background will be used only to describe the types of students completing the survey. The information will not be used to find out your name. No names will ever be asked for.

1. What is your birthdate?

Month

Year

2. What is your sex?

a. Male

b. Female

3. Which school do you attend?

a. School A

b. School B

4. What is your average overall GPA in school? (check one):
a. $4.0-3.5$
b. $3.4-3.0$
c. $2.9-2.5$
d. $2.4-2.0$
e. 2.0 or below

5. Ethnic/racial background (if you are more than one race, check all that applies):
a. African American (Black)
b. American Indian
c. Asian American
d. Latino (Hispanic)
e. White American
f. Other

6. During the current 2008-2009 school year, have you been employed outside of school? If so, approximately how many hours a week do you work? If you did not work, please check "0 hours"
a. 0 hours
b. 1-4 hours
c. 5-9 hours
d. 10-14 hours
e. 15-19 hours
f. 20 or more hours 


\section{Substance Use Behavior Survey}

1. Have you ever tried cigarette smoking, even one or two puffs?
a. Yes
b. No

2. How old were you when you smoked a whole cigarette for the first time?
a. I have never smoked a whole cigarette
b. 8 years old or younger
c. 9 or 10 years old
d. 11 or 12 years old
e. 13 or 14 years old
f. 15 or 16 years old
g. 17 years old or older

3. During the past 30 days, on how many days did you smoke cigarettes?
a. 0 days
b. 1 or 2 days
c. 3 to 5 days
d. 6 to 9 days
e. 10 to 19 days
f. 20 to 29 days
g. All 30 days

4. During the past 30 days, on the days you smoked, how many cigarettes did you smoke per day?
a. I did not smoke cigarettes during the past 30 days
b. Less than 1 cigarette per day
c. 1 cigarette per day
d. 2 to 5 cigarettes per day
e. 6 to 10 cigarettes per day
f. 11 to 20 cigarettes per day
g. More than 20 cigarettes per day

5. During the past 30 days, how did you usually get your own cigarettes? (Select only one response)
a. I did not smoke cigarettes during the past 30 days
b. I bought them in a store such as a convenience store, supermarket, discount store, or gas station
c. I bought them from a vending machine
d. I gave someone else money to buy them for me
e. I borrowed (or bummed) them from someone else
f. A person 18 years old or older gave them to me
g. I took them from a store of family member
h. I got them some other way 
6. Have you ever smoke cigarettes daily, that is, at least one cigarette every day for 30 days?
a. Yes
b. No

7. During the past 30 days, on how many days did you use chewing tobacco, snuff, or dip, such as Redman, Levi Garrett, Beechnut, Skoal, Skoal Bandits, or Copenhagen?
a. 0 days
b. 1 or 2 days
c. 3 to 5 days
d. 6 to 9 days
e. 10 to 19 days
f. 20 to 29 days
g. All 30 days

8. During the past 30 days, on how many days did you smoke cigars, cigarillos, or little cigars?
a. 0 days
b. 1 or 2 days
c. 3 to 5 days
d. 6 to 9 days
e. 10 to 19 days
f. 20 to 29 days
g. All 30 days

The next 5 questions ask about drinking alcohol. This includes drinking beer, wine, wine coolers, and liquor such as rum, gin, vodka, or whiskey. For these questions, drinking alcohol does not include drinking a few sips of wine for religious purposes.

1. During your life, on how many days have you had at least one drink of alcohol?
a. 0 days
b. 1 or 2 days
c. 3 to 9 days
d. 10 to 19 days
e. 20 to 39 days
f. 40 to 99 days
g. 100 or more days

2. How old were you when you had your first drink of alcohol other than a few sips?
a. I have never had a drink of alcohol other than a few sips
b. 8 years old or younger
c. 9 or 10 years old
d. 11 or 12 years old
e. 13 or 14 years old
f. 15 or 16 years old
g. 17 years old or older 
3. During the past 30 days, on how many days did you have at least one drink of alcohol?
a. 0 days
b. 1 or 2 days
c. 3 to 5 days
d. 6 to 9 days
e. 10 to 19 days
f. 20 to 29 days
g. All 30 days

4. During the past 30 days, on how many days did you have 5 or more drinks of alcohol in a row, that is, within a couple of hours?
a. 0 days
b. 1 day
c. 2 days
d. 3 to 5 days
e. 6 to 9 days
f. 10 to 19 days
g. 20 or more days

5. During the past 30 days, how did you usually get the alcohol you drank?

a. I did not drink alcohol during the past 30 days

b. I bought them in a store such as a convenience store, supermarket, discount store, or gas station

c. I bought it at a restaurant, bar, or club

d. I bought it at a public event such as concert or sporting event

e. I gave someone else money to buy it for me

f. Someone gave it to me

g. I took them from a store or family member

h. I got them some other way

The next 3 questions ask about marijuana use. Marijuana also is called grass or pot.

1. During your life, on how many days have you used marijuana?
a. 0 times
b. 1 or 2 times
c. 3 to 9 times
d. 10 to 19 times
e. 20 to 39 times
f. 40 to 99 times
g. 100 or more time 
2. How old were you when you had you tried marijuana for the first time?
a. I have never tried marijuana
b. 8 years old or younger
c. 9 or 10 years old
d. 11 or 12 years old
e. 13 or 14 years old
f. 15 or 16 years old
g. 17 years old or older

3. During the past 30 days, on how many days did you have at least one drink of alcohol?
a. 0 days
b. 1 or 2 days
c. 3 to 5 days
d. 6 to 9 days
e. 10 to 19 days
f. 20 to 29 days
g. All 30 days

The next 8 questions ask about other drugs.

1. During your life, how many times have you used any form of cocaine, including powder, crack, or freebase?
a. 0 times
b. 1 or 2 times
c. 3 to 9 times
d. 10 to 19 times
e. 20 to 39 times
f. 40 or more times

2. During the past 30 days, how many times did you use any form of cocaine, including powder, crack, or freebase?
a. 0 times
b. 1 or 2 times
c. 3 to 9 times
d. 10 to 19 times
e. 20 to 39 times
f. 40 or more times 
3. During your life, how many times have you sniffed glue, breathed the contents of aerosol spray cans, or inhaled any paints or sprays to get high?
a. 0 times
b. 1 or 2 times
c. 3 to 9 times
d. 10 to 19 times
e. 20 to 39 times
f. 40 or more times

4. During your life, how many times have you used heroin (also called smack, junk, or China White)?
a. 0 times
b. 1 or 2 times
c. 3 to 9 times
d. 10 to 19 times
e. 20 to 39 times
f. 40 or more times

5. During your life, how many times have you used methamphetamines (also called speed, crystal, crank, or ice)?
a. 0 times
b. 1 or 2 times
c. 3 to 9 times
d. 10 to 19 times
e. 20 to 39 times
f. 40 or more times

6. During your life, how many times have you used ecstasy (also called MDMA)?
a. 0 times
b. 1 or 2 times
c. 3 to 9 times
d. 10 to 19 times
e. 20 to 39 times
f. 40 or more times

7. During your life, how many times have you taken steroid pills or shots without a doctor's prescription?
a. 0 times
b. 1 or 2 times
c. 3 to 9 times
d. 10 to 19 times
e. 20 to 39 times
f. 40 or more times 
8. During your life, how many times have you used a needle to inject any illegal drug into your body?
a. 0 times
b. 1 time
c. 2 times
d. 3 times
e. 4 times
f. 5 or more times 
This section of the survey asks you to please check mark the activities that you are (or have participated in this school year (School Year 2008-2009). Please answer the questions on the survey itself. When you check mark that you have participated in an activity, on the space beside that activity please make your best estimate as to how many hours a week after school and on the weekends you spend being involved in that activity.

\section{SPORTS ACTIVITIES}

In the current school year, do you (did you) participate in any of the following school teams (varsity, junior varsity, or other organized school program) outside of Physical Education?

(Check all that apply)

Baseball

_ Basketball

_ Cheerleading

_ Soccer

__ Football

_ Softball

_ Swimming

Tennis

_ Golf

Tennis

_ Track/Cross Country

Volleyball

_ Wrestling

Other (Please Specify)

\section{TIME USE}

Please indicate approximately how many hours a week you spend participating in that activity. 


\section{PERFORMING ARTS ACTIVITIES}

Which of the following performing arts activities at school do you (did you)

participate in this school year?

(Check all that apply)

Art

_ Band or Orchestra/Strings

Choir

_ Theatre/Drama

Marching Band

Other (Please Specify)

\section{TIME USE}

For those activities you are involved in, please indicate approximately how many hours a week you spend participating in that activity.

\section{COMMUNITY BASED ACTIVITIES}

TIME USE

Do you (did you) participate in any

of the following clubs or activities

outside of school? (Check all that apply)

__ Athletic/recreational club

_ Pop or Rock band

_ Boy Scouts/Girl Scouts

- 4-H

_ Church groups

_ Volunteer/service work

Other (Please Specify) 


\section{ACADEMIC CLUBS}

Which of the following academic clubs at school do you (did you) participate in this school year? (Check all that apply)

\section{BABES/TATU}

_ Christian Club

_ DECA

_ Interact

__ Foreign language club

__ Key Club

_ Student Council

__ Pep club/Boosters

_ JROTC

_ S.A.D.D.

__ Science fair

__ School Yearbook

Other (Please Specify)

\section{TIME USE}

Please indicate approximately how many hours a week you spend participating in that activity. 